\title{
STUDIES ON STREPTOCARPUS
}

\section{GENETICS AND CHEMISTRY OF FLOWER COLOUR IN THE GARDEN FORMS, SPECIES AND HYBRIDS}

\author{
W. J. C. LAWRENCE and V. C. STURGESS * \\ John Innes Horticultural Institution, Hertford, Herts
}

Received I8.ii.57

\section{INTRODUCTION}

IN a previous paper (Lawrence et al., I939) a first account $\dagger$ was given of the genetics and chemistry of flower colour in the garden forms of Streptocarpus $(2 n=32)$. This paper deals mainly with aspects of gene action and interaction in pigment production, the latter being of special interest.

\section{CHEMISTRY OF FLOWER COLOUR}

The structural formulæ of the anthocyanidin (sugar-free) pigments relevant to Streptocarpus are given in fig. I. Peonidin is described as a derivative (by partial methylation) of cyanidin and similarly petunidin and malvidin are derivatives of delphinidin.

Anthocyanidins do not occur free in nature but in combination with one or more molecules of a sugar, the compound being an anthocyanin. One molecule of sugar is always situated at position 3- (monose). If a second one is present, it may either be attached to the first one (biose) or linked with the anthocyanidin at position 5(dimonoside) ; for glycoside terminology see Robinson and Robinson, 1932. In Streptocarpus flowers the anthocyanidin glycosides are of three kinds: (i) 3-monoside, having one hexose molecule at position 3- on the pigment molecule, (ii) 3-pentoseglycoside, having both a hexose and a pentose molecule at position 3 - and (iii) $3: 5$-dimonoside, having one hexose molecule at position 3 - and another at position 5-, fig. $2 .+$

Another group of sap-soluble pigments, ranging in colour from near white to yellow, is conveniently denoted by the term " anthoxanthin" (flavones, flavonols, flavanones) and to avoid circumlocation we shall include chlorogenic acid under this heading. Some anthoxanthins have the property of making some anthocyanins bluer and these are described as co-pigments (Robinson and Robinson, I93I).

* Biochemist, now of the Royal Infirmary, Leicester.

T The work in progress was suddenly broken-up by the outbreak of the 1939-45 war, at the point where a general survey had been completed but the more intensive investigations had barely begun. Post-war changes in the authors responsibilities have delaye 1 analysis and publication of results.

\pm Recent findings (p. 324) suggest that two types of glycoside with sugars in both 3and 5-positions are present, but the term $3: 5$-dimonoside is retained throughout this paper pending further work on thcse glycosides. 
Two nearly colourless anthoxanthins, one of them a co-pigment, occur in Streptocarpus flowers.

\section{GENETICS OF GARDEN FORMS}

\section{(i) Anthocyanins}

The garden forms of Streptocarpus originated 70 years ago, from crosses between $S$. dunnii Mast., S. rexii Lind., and S. parviflorus Hook, made by W. Watson at the Royal Botanic Gardens, Kew. Selection by nurserymen during the next twenty years led to the establishment of the garden forms much as we know them to-day. For all practical purposes they may be regarded as forms of $S$. rexii into which have been bred three major flower colour genes from $S$. dunnii, fig. 2. Thus,

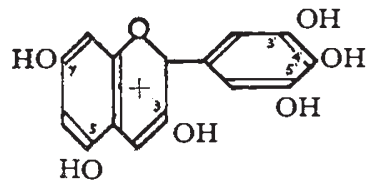

Delphinidin

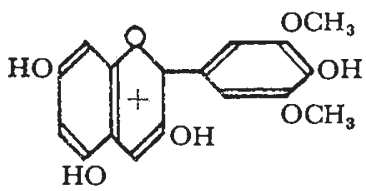

Malvidin $(O(R) M)^{*}$

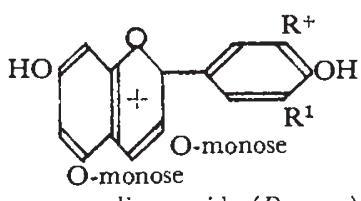

3:5-dimonoside $(D--)$
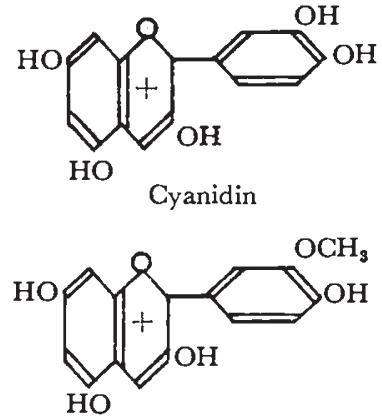

Peonidin $(o R M)$

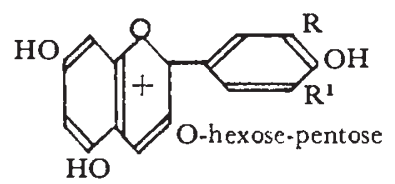

3-pentoseglycoside $(d P-)$

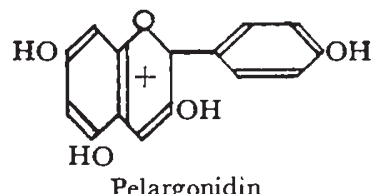

Pelargonidin
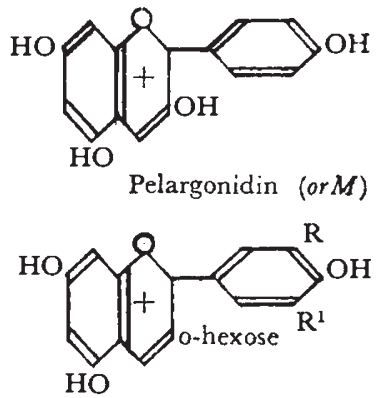

3-monoside $(d p Q)$

FIG. I.

Structural formulæ for flower pigments relevant to Streptocarpus.

Upper line: the three main naturally occurring anthocyanidins.

Middle line: the three main anthocyanidins in Streplocarpus.

Lower line: three glycosides in Streptocarpus.

Any one of the glycosides may be associated with any one of the anthocyanidins (mictdle line).

* petunidin, $3^{\prime}$-methyl delphinidin, is sometimes found associated with malvidin, but is not considered in this paper.

+ where $\mathrm{R}$ and $\mathrm{R}^{1}$ may be $\mathrm{H}, \mathrm{OH}$, or $\mathrm{OCH}_{3}$.

although disturbed ratios may occur in breeding experiments with garden forms, their interspecific hybridity is not otherwise obvious.

Four main pairs of genes controlling flower colour in Streptocarpus have been identified previously (Lawrence et al., 1939). Their phenotypic effects are as follows :-

$V$, necessary for general production of anthocyanin in leaves and flower stems. 
$F$ (previously $A$ ), with $V$, necessary for the general production of anthocyanidin in the flowers. In the presence of $r$ and $o$ (see below), the anthocyanidin is pelargonidin. Incompletely dominant.

$R$, substitutes a hydroxyl at position $3^{\prime}$ - giving cyanidin in place of pelargonidin. Dominant.

$a$, epistatic to $R$. Substitutes two hydroxyls, one at position $3^{\prime}$ and one at $5^{\prime}-$, giving delphinidin in place of pelargonidin (or cyanidin). Dominant.

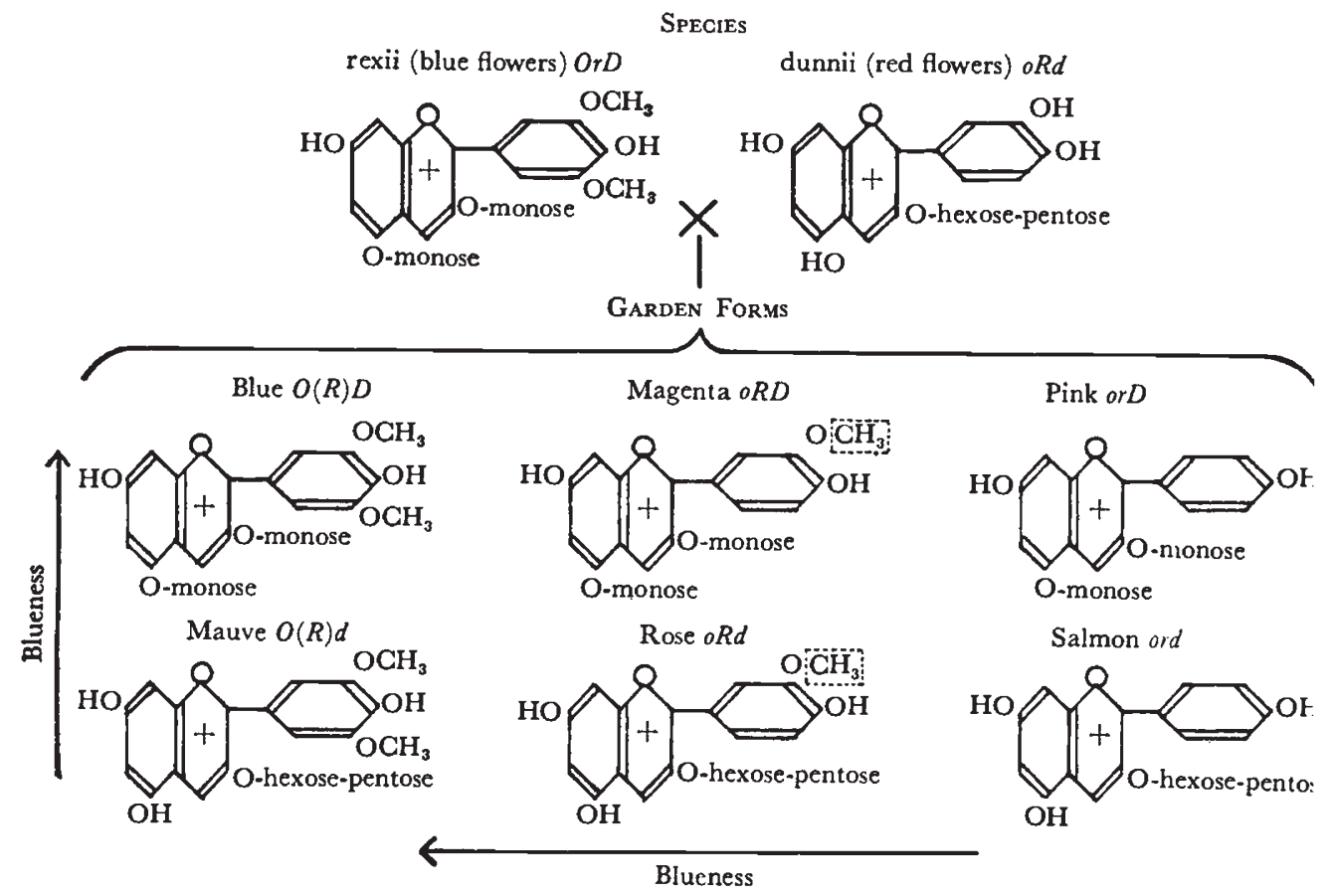

Frg. 2.-Chemical and genetical scheme for the inheritance of the main anthocyanins in the garden forms of Streptocarpus, showing their origin from artificial species hybridisation. The white-flowered Streptocarpus parviflorus was a third parent in this hybridisation and has the genetic constitution $O R D$.

$D$, produces $3: 5$-dimonoside in place of mixtures of 3 -pentoseglycoside and $3: 5$-dimonoside $(d)$ or 3 -monoside and $3: 5$ dimonoside. Dominant.

Different combinations of these five pairs of genes give seven distinct classes for flower colour, viz. :- blue $(A O R D$ and $A O r D)$, mauve (AORd and $A O r d)$, magenta $(A o R D)$, rose $(A o R d)$, pink $($ Aor $D)$ and salmon $($ Aord $)$. Fig. 2 summarises the origin and main genotypes and pigments of the garden forms.

The existence of $V$ became known when a wild, white-flowered variant of rexii, viz. rexii $F B$, completely devoid of anthocyanin in flowers, flower stems and leaves, was introduced into the experiments.

White-flowered garden forms in our material usually have some 
anthocyanin in the leaves and invariably in the flower stems which, in general, are conspicuously pigmented. On crossing rexii $F B$ with

TABLE I

Showing interaction of genes $\mathrm{V}$ and $\mathrm{F}$ in floral pigmentation

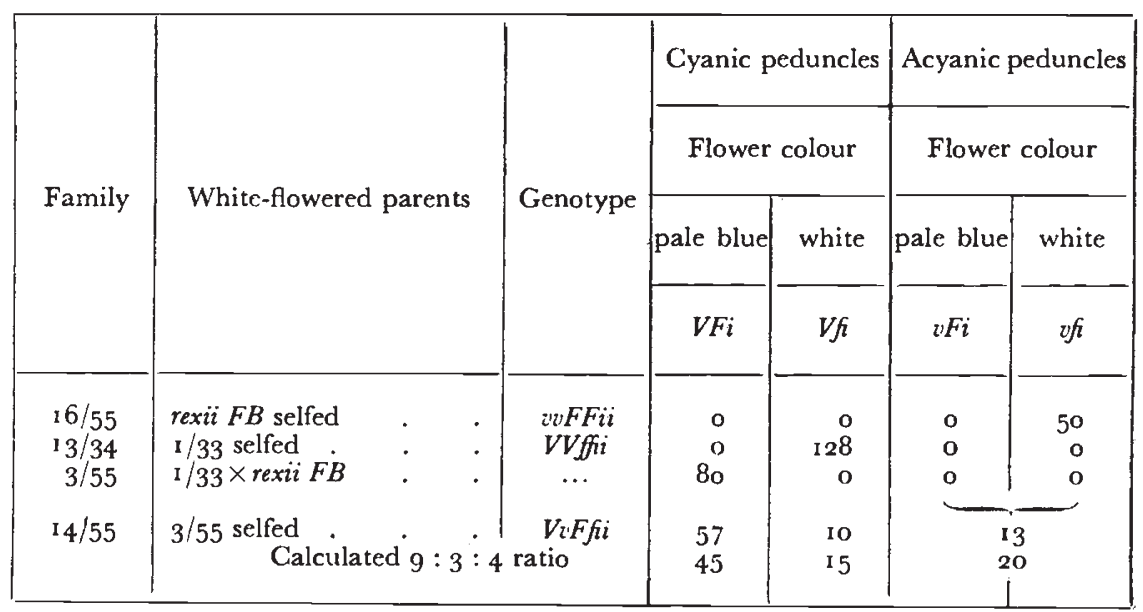

appropriate garden forms, the progenies revealed that two complementary genes, $V$ and $F$, were required to account for the inheritance of anthocyanidin in the flowers (table I). All forms carrying

TABLE 2

Some characteristic phenotypes and their genotypes

\begin{tabular}{|c|c|c|}
\hline \multicolumn{2}{|c|}{ Phenotype (anthocyanin) } & \multirow{2}{*}{ Genotype } \\
\hline $\begin{array}{c}\text { Flower stems (also calyxes } \\
\text { and leaves in varying degree) }\end{array}$ & Corollas & \\
\hline & & \\
No pigment (green) & Pure white, or very faintly tinged & rexii $F B:-$ \\
& & rFi \\
Pigment (red) & Pure white & Garden forms :- \\
Pigment (red) & Pale anthocyanin \\
Pigment (red) & Medium to deep anthocyanin & $V F i$ \\
& & $V F I$ \\
\hline
\end{tabular}

$V$ are identifiable on sight by their pigmented flower stems. A third gene $I$ intensifies the anthocyanidin produced in the flowers by $V$ and $F$. Some characteristic phenotypes and their genotypes are given in table 2 and the separate inheritance of $V, F$ and $I$ is summarised in table 3 .

Re-examination of the older records of anthocyanin intensity in the garden forms showed that of the many hundreds of families recorded, only a few had distinct intensity classes and to these the $V F I$ scheme can be fitted (table 4). The action of $I$ can be identified 
with certainty only in families uniformly homozygous or heterozygous for $F$ (table 4 ) because, in most cases $F$ and $I$ are each cumulative in

TABLE 3

Inheritance of $\mathrm{V} \mathrm{r}, \mathrm{Ff}$ and $\mathrm{li}$

\begin{tabular}{|c|c|c|c|c|c|c|c|}
\hline \multirow{2}{*}{\multicolumn{2}{|c|}{ Ciross or self }} & \multirow{2}{*}{$\begin{array}{c}\text { No. of } \\
\text { families }\end{array}$} & \multirow{2}{*}{$\begin{array}{l}\text { Progeny } \\
X: x\end{array}$} & \multicolumn{2}{|c|}{$x^{2}$} & \multirow{2}{*}{$\begin{array}{l}\text { Degree } \\
\text { of } \\
\text { freedom }\end{array}$} & \multirow[b]{2}{*}{$P$} \\
\hline & & & & Deviation & & & \\
\hline$V u \times i v$ & . & 5 & $\begin{array}{c}I: I \\
93: 94\end{array}$ & 0.005 & $\cdots$ & I & 0.95 \\
\hline$F f \times f f$. & . & 2 & $44: 6 I$ & $2 \cdot 75^{2}$ & I 2.779 & $\begin{array}{l}4 \\
1\end{array}$ & $\begin{array}{l}0.02-0.01 \\
0.1-0.05\end{array}$ \\
\hline$I i \times i i$ & & 3 & $7^{2}: 95$ & $3 \cdot 168$ & $\begin{array}{c}0.896 \\
\ldots \\
0.86_{3}\end{array}$ & $\begin{array}{l}1 \\
1 \\
2\end{array}$ & $\begin{array}{l}0.5-10.10 \\
0.10-0.05 \\
0.90-0.50\end{array}$ \\
\hline$V v I i \times v i i i$ & . & 6 & $\begin{array}{c}1: 1: 2 \\
54: 52: 105\end{array}$ & 0.043 & 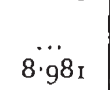 & $\begin{array}{r}2 \\
10\end{array}$ & $\begin{array}{l}0.98-0.95 \\
0.90-0.50\end{array}$ \\
\hline$F f i \times F f I i$ & . & 2 & $\begin{array}{c}3: 3: 2 \\
31: 28: 18\end{array}$ & 0.284 & $\begin{array}{c}\ldots \\
0.264\end{array}$ & $\begin{array}{l}\text { I } \\
3\end{array}$ & $\begin{array}{l}0.90-0.50 \\
0.98-0.95\end{array}$ \\
\hline VuFfii selfed & & 3 & $\begin{array}{c}9: 7 \\
68: 45\end{array}$ & 0.708 & $\begin{array}{c}\ldots \\
1 \cdot 023\end{array}$ & $\begin{array}{l}1 \\
2\end{array}$ & $\begin{array}{l}0.90-0.50 \\
0.90-0.50\end{array}$ \\
\hline VuIi selfed & . & 3 & $\begin{array}{r}9: 3: 4 \\
64: 29: 18\end{array}$ & $6 \cdot 686$ & $\begin{array}{c}\ldots \\
0.782\end{array}$ & $\begin{array}{l}2 \\
4\end{array}$ & $\begin{array}{l}0.05-0.02 \\
0.95-0.90\end{array}$ \\
\hline$V v$ selfed & . & I & $\begin{array}{c}3: 1 \\
31: 14\end{array}$ & 0.896 & $\ldots$ & I & $0.50-0.10$ \\
\hline
\end{tabular}

TABLE 4

Inheritance of $\mathrm{Ii}$

\begin{tabular}{|c|c|c|c|c|c|}
\hline \multirow{2}{*}{ Family } & \multirow{2}{*}{ Parents } & \multicolumn{4}{|c|}{ Anthocyanin intensity } \\
\hline & & Very deep & Deep & Medium & Pale \\
\hline $\begin{array}{l}2 / 34 \\
5 / 34\end{array}$ & $\begin{array}{l}3 / 33(F F I) \text { selfed } \\
2 / 33(F F I I) \text { selfed }\end{array}$ & $\begin{array}{l}14 \\
99\end{array}$ & $\begin{array}{r}62 \\
0\end{array}$ & $\begin{array}{r}4^{\circ} \\
0\end{array}$ & $\begin{array}{l}0 \\
0\end{array}$ \\
\hline $8 / 34$ & $2 / 33(F F I I) \times 3 / 33(F F I i)$ & \multicolumn{2}{|c|}{$\underbrace{47}$} & o & o \\
\hline $14 / 34$ & $1 / 33(f f i) \times 2 / 33(F F I i)$ & 0 & \multicolumn{2}{|c|}{ I09 } & 0 \\
\hline $6 / 34$ & $3 / 33($ FFIi $) \times 1 / 33(f f i)$ & o & 0 & 45 & 54 \\
\hline $13 / 35$ & $8^{2} / 34(F F i i)$ selfed & 0 & 23 & 58 & 23 \\
\hline $84 / 36$ & $13^{15} / 35(F F I i)$ selfed & 77 & 24 & 0 & o \\
\hline $102 / 38$ & I6/34 $(F F I i) \times \mathrm{I} / 33(f f i)$ & 0 & $4^{8}$ & 45 & 0 \\
\hline
\end{tabular}

action and dosage effects prevent the distinguishing of $V F I$ from $V F i$ genotypes.

Anthocyanin intensity in typical $S$. rexii, the pale-blue-flowered ancestral parent of the garden forms, is practically identical with that of $V F i$ garden genotypes, whereas the deeper intensity of $S$. 
dunnii, another ancestral parent, is similar to that of $V F I$ forms. This suggests that just as the genes $O$ and $D$ were contributed by rexii and $R$ by dunnii, so $i$ is derived from rexii and $I$ from dunnii.

It can now be seen that, whereas $V, F$ and $I$ are concerned with the general production of anthocyanin in the flowers, $O, R$ and $D$ modify the structure of the anthocyanin molecule and in this sense may be said to be specific. The terms "general" and "specific" have been used by Scott-Moncrieff (I939) in a special genetic sense.

TABLE 5

\begin{tabular}{|c|c|c|c|}
\hline $\begin{array}{l}\text { Flower } \\
\text { colour }\end{array}$ & & $\begin{array}{l}\text { Genotypes } \\
\text { tested } \\
\text { (all } V V F F)\end{array}$ & Anthocyanins \\
\hline Blue. & . & $\begin{array}{l}\text { OORRDd } \\
\text { OoRRDd } \\
\text { OoRrDd }\end{array}$ & $\begin{array}{l}\text { Malvidin } 3: 5 \text {-dimonoside. Plus, usually, traces of } \\
\text { anthocyanin giving } \mathrm{Fe}+\text { reaction.* }\end{array}$ \\
\hline Magenta & . & $\begin{array}{l}\text { ooRRDd } \\
\text { ooRrDD } \\
\text { ooRrDd }\end{array}$ & $\begin{array}{l}\text { Peonidin } 3: 5 \text {-dimonoside. Plus varying amounts of } \\
\text { cyanidin } 3: 5 \text {-dimonoside. }\end{array}$ \\
\hline Pink. & . & $\begin{array}{l}\operatorname{oorr} D D \\
\text { oorr } D d\end{array}$ & $\begin{array}{l}\text { Pelargonidin diglycoside. Plus traces of cyanidin di- } \\
\text { glycoside. }\end{array}$ \\
\hline Mauve & . & $\begin{array}{l}\text { OORRdd } \\
\text { OoRRdd } \\
\text { OoRrdd } \\
\text { OOrrdd } \\
\text { Oorrdd }\end{array}$ & $\begin{array}{l}\text { Malvidin } 3 \text {-pentoseglycoside (or } 3 \text {-monoside } \dagger \text { ). Plus } \\
\text { trace of } \mathrm{Fe}+\text { anthocyanin, plus malvidin } 3: 5 \text {-di- } \\
\text { monoside containing slight traces of } \mathrm{Fe}+\text { anthocyanin. }\end{array}$ \\
\hline Rose . & . & $\begin{array}{l}\text { ooRRdd } \\
\text { ooRrdd }\end{array}$ & $\begin{array}{l}\text { Peonidin 3-pentoseglycoside (or 3-monoside } \dagger \text { ). Plus } \\
\text { some cyanidin 3-pentoseglycoside (or 3-monoside), } \\
\text { plus peonidin } 3: 5 \text {-dimonoside, plus trace of cyanidin } \\
3: 5 \text {-dimonoside. }\end{array}$ \\
\hline Salmon & . & oorrdd & $\begin{array}{l}\text { Pelargonidin 3-pentoseglycoside (or } 3 \text {-monoside } \dagger \text { ), plus } \\
\text { pelargonidin diglycoside. Traces of cyanidin glycosides } \\
\text { are often present. }\end{array}$ \\
\hline
\end{tabular}

* $\mathrm{Fe}+$ refers to the positive ferric reaction given by delphinidin, petunidin and cyanidin, i.e. pigments containing an $o$ - dihydroxyl group.

$\dagger$ Rarely, a little monoside may accompany pentoseglycoside or vice versa.

In this paper their usage is purely descriptive: "general" refers to pigment production without regard to the actual type produced and "specific" to a definite modification of the pigment molecule. The anthocyanins identified in seventeen different garden genotypes tested are listed in table 5 .

\section{(ii) Anthoxanthins}

An ivory-white anthoxanthin has been found to act as a co-pigment and can therefore be recognised visually in cyanic flowers by its blueing action. On a visual assessment the inheritance of the copigment is controlled by a single gene $(C)$ (table 6). Chemical tests show that $c c$ individuals sometimes contain a little pigment; $C$ is 
concerned, along with $O, R$ and $D$, in specific flower pigmentation. Chromatographic tests showed that apigenin glycosides (fig. 3) are the only flavones present in quantity in flowers containing co-pigment i.e. $C$ flowers. Since apigenin glycosides are known to be co-pigments in other genera, we may assume that they have the same function in Streptocarpus.

TABLE 6

Inheritance of the co-pigment $(\mathrm{C})$

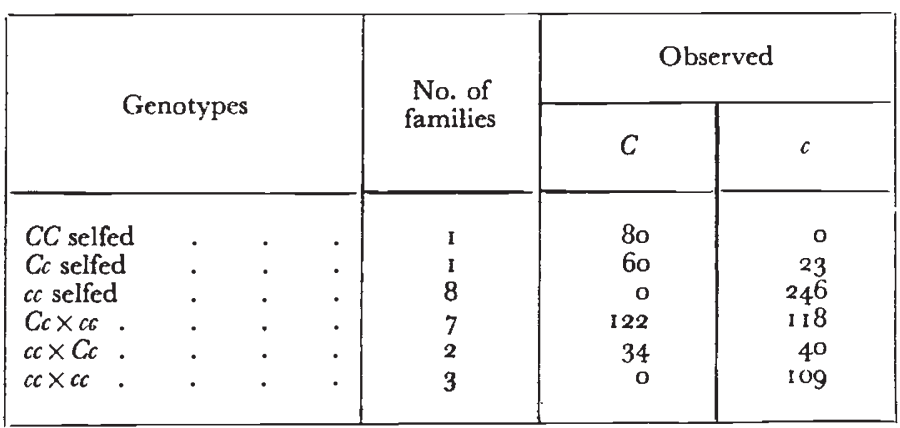

Pooled BI data. $\chi^{2}=0.006$, I D.F. $P=0.95-0.90$ $x^{2}=2.89$, 8 D.F. $P=0.95-0.90$

A second anthoxanthin is found in all the many garden forms tested. It is not a co-pigment. This was proved by extracting the anthoxanthins from two sibs, a blue-mauve $(C)$ and a red-mauve $(c)$ and adding each anthoxanthin to the anthoxanthin-free anthocyanin

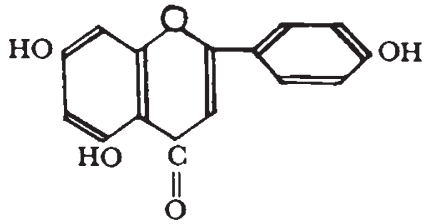

Apigenin

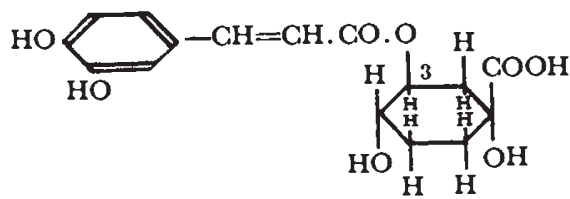

Chlorogenic acid.

Fig. 3.-Structural formulæ for apigenin (co-pigment) and chlorogenic acid (non-co-pigment).

solutions from the same blue- and red-mauve plants. The anthoxanthin from the blue-mauve $(C)$ strongly co-pigmented the anthocyanin from the red-mauve $(c)$ whereas the anthoxanthin from the red-mauve did not co-pigment the anthocyanin from the blue-mauve plant. From analysis, using partition chromatography, the non-co-pigment appears to be chlorogenic acid (fig. 2). In passing, it may be noted that the constitution of rexii for co-pigment is $C C$ and dunnii cc.

\section{(iii) Methylation}

In Streptocarpus and other genera, the $3^{\prime}$ - and $5^{\prime}$-hydroxyl groups of the anthocyanidins may or may not be methylated, that is, have the hydrogen atom of the hydroxyl group replaced by a methyl group 
(fig. I). Methylation of the $4^{\prime}$-hydroxyl is not found in nature, therefore, all pelargonidin forms are unmethylated.

As will be seen from fig. 2, the anthocyanin in $S$. rexii $(O r)$, one of the parents of the garden forms, is methylated, whereas in the other parent, $S$. dunnii $(o R)$ it is not, i.e. gene $O$ in rexii produces malvidin and gene $R$ in dunnii cyanidin (or forms contain pelargonidin). When, however, we examined the garden forms, $R$ was found to give, not cyanidin, as in dunnii but the methylated analogue, peonidin. Further, crossing a garden rose ( $O R$, peonidin) or salmon (or, pelargonidin) to dunnii (oR, cyanidin) gave peonidin in the $\mathrm{F}_{1}$, not cyanidin. Thus, $R$ gives unmethylated pigment in dunnii but methylated pigment in the garden forms. The simplest explanation of this situation is that

TABLE ?

Inheritance of methylation

\begin{tabular}{|c|c|c|c|c|c|c|c|c|c|c|c|c|}
\hline Genotype & \multicolumn{9}{|c|}{0} \\
\hline $\begin{array}{c}\text { Percentage } \\
\text { methylation } \\
\text { class means: }\end{array}$ & 100 & 87.5 & $62 \cdot 5$ & 37.5 & $12 \cdot 5$ & 0 & 100 & 87.5 & 62.5 & 37.5 & 12.5 & 0 \\
\hline $1 / 37$ selfed & 5 & 2 & 7 & 2 & 1 & 0 & 0 & 0 & 0 & 0 & 0 & 2 \\
\hline $1 / 37 \times$ dunnii & 5 & 2 & 4 & 2 & 1 & 1 & 1 & 5 & 5 & 4 & 4 & 15 \\
\hline $2 / 37 \times$ dunnii & 11 & 12 & 7 & 2 & 2 & 3 & 11 & 2 & 2 & 2 & 2 & 7 \\
\hline B1 totals & 16 & 14 & 11 & 4 & 3 & 4 & 12 & 7 & 7 & 6 & 6 & 22 \\
\hline
\end{tabular}

nearly all garden forms are homozygous for a dominant gene for methylation. In fact out of 133 individuals tested, only two were unmethylated. S. dunnii may, therefore, be tentatively designated $o R m$, and the above mentioned garden forms $o R M$, where $M$ indicates a gene or genes for methylation.

Some evidence on the inheritance of methylation has been obtained from derivatives of rexii $\times$ dunnii $(\mathrm{I} / 37$ ) and rexii $L$ (a wild form related to rexii) $\times$ dunnii $(2 / 37)$. rexii and dunnii are widely different species and the fertility of $F_{1}$ (completely methylated) and $B_{1}$ crosses is greatly reduced, e.g. one capsule of rexii normally produces some 2000 seeds, whereas the corresponding figure for the $F_{1}$ and $B_{1}$ capsules is of the order ro and roo respectively. Because of the high mortality of gametes or zygotes consistent segregation, in different families, of methylated and unmethylated progeny in terms of Mendelian ratios could hardly be expected. The results of the above crosses are given in table 7 , the progeny being divided into six arbitrary classes for degree of methylation and distinguishing between $O$ and 0 genotypes. 
As will be seen, in both $F_{2}$ and $B_{1}$ (and in both $O$ and 0 genotypes) completely unmethylated forms are at once recovered, and in $B_{1}$ totals the proportions of completely methylated and unmethylated progeny are sufficiently high as to suggest that a simple genetic system governs the inheritance of methylation.

\section{(iv) Glycosidation}

In discussing glycosides, we shall use the terms " primary" and "secondary" to distinguish dimonoside produced in $D$ forms from that produced in $d$.

(a) Primary dimonoside. $D$ produces $3: 5$-dimonoside and, on visual assessment of flower colour, we had previously reported this gene to be completely dominant. Chemical assessment of flower pigment now shows that its dominance depends in part on the presence of $O$ and $R$ (see table 12). Out of $25 D d$ forms tested, twenty contained roo per cent. dimonoside and five 98, 90, 90, 85 and 80 per cent. respectively.

(b) Secondary dimonoside. In the absence of $D$, the anthocyanin generally consists of a mixture of either 3-pentoseglycoside or 3monoside with $3: 5$-dimonoside. In these mixtures, the proportion of dimonoside in garden forms varies more or less continuously from 20 to 95 per cent. Selection of types with high or low dimonoside content yielded forms that were largely or altogether true breeding for high or low dimonoside. Data which could be clearly interpreted were obtained by crossing selected garden forms to the two true breeding species, dunnii and rexii, which were also crossed with one another. The general position may be stated as follows :-

I. certain $d d$ garden forms when selfed breed true for low dimonoside ;

2. certain low dimonoside varieties when crossed give only low dimonoside forms in $\mathrm{F}_{1}$;

3. S. dunnii breeds true for low dimonoside ;

4. certain low dimonoside varieties crossed to dunnii give only high dimonoside forms in $F_{1}$;

5. certain garden forms breed true for high dimonoside.

These results can be explained by postulating two pairs of complementary genes responsible for secondary dimonoside production in $d d$ genotypes, the low dimonoside garden varieties being $X X z z$ in constitution, dunnii (low) $x x Z Z$ and the $\mathrm{F}_{1}$ 's (high) $X x Z Z$. If this postulation is correct, it should be possible to get low dimonoside $(x x Z Z)$ forms from backcrossing the high dimonoside $F_{1}$ 's to dunnii and these should then give low dimonoside progeny in $\mathrm{B}_{2}$ with dunnii. This was found to be the case and the results are given below (table 8). The percentage figures refer to the amount of secondary dimonoside. It will be noticed that in families $49 / 38$ and $57 / 38$ less than I oo per cent. dimonoside is produced by the double heterozygote $X x Z z$, and slightly less than Ioo per cent. pentoseglycoside by the homozygous dunnii, $x x Z Z$. 
TABLE 8

Pedigree showing constitution of dunnii and two garden forms for the complementary genes $\mathrm{X}$ and $\mathrm{Z}$ controlling the production (amount per cent.) of secondary dimonoside

(a)

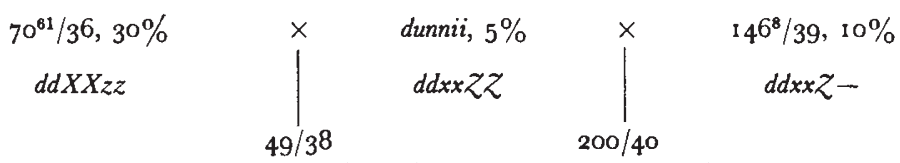

30 plants, $90 \% X x Z z \quad 8$ plants, $10 \% x x Z-$

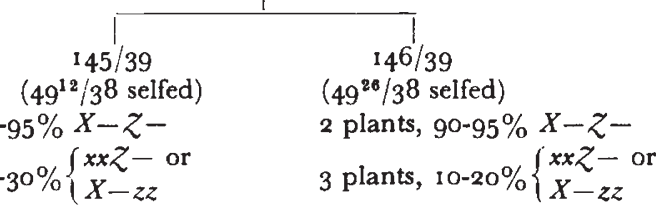

(b)
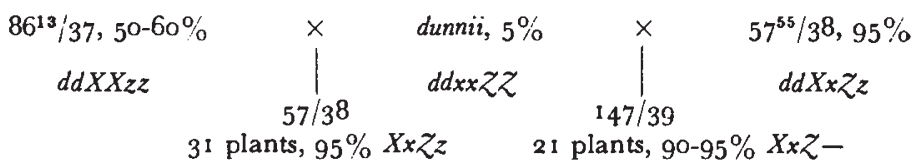

31 plants, $95 \% X x Z z \quad 21$ plants, $90-95 \% X x Z-$

14 plants, $10-40 \% x x Z-$

\section{TABLE 9}

Pedigree showing constitution of rexii for $\mathrm{X}$

Amounts of primary $(D)$ and secondary $(d)$ dimonoside in per cent.

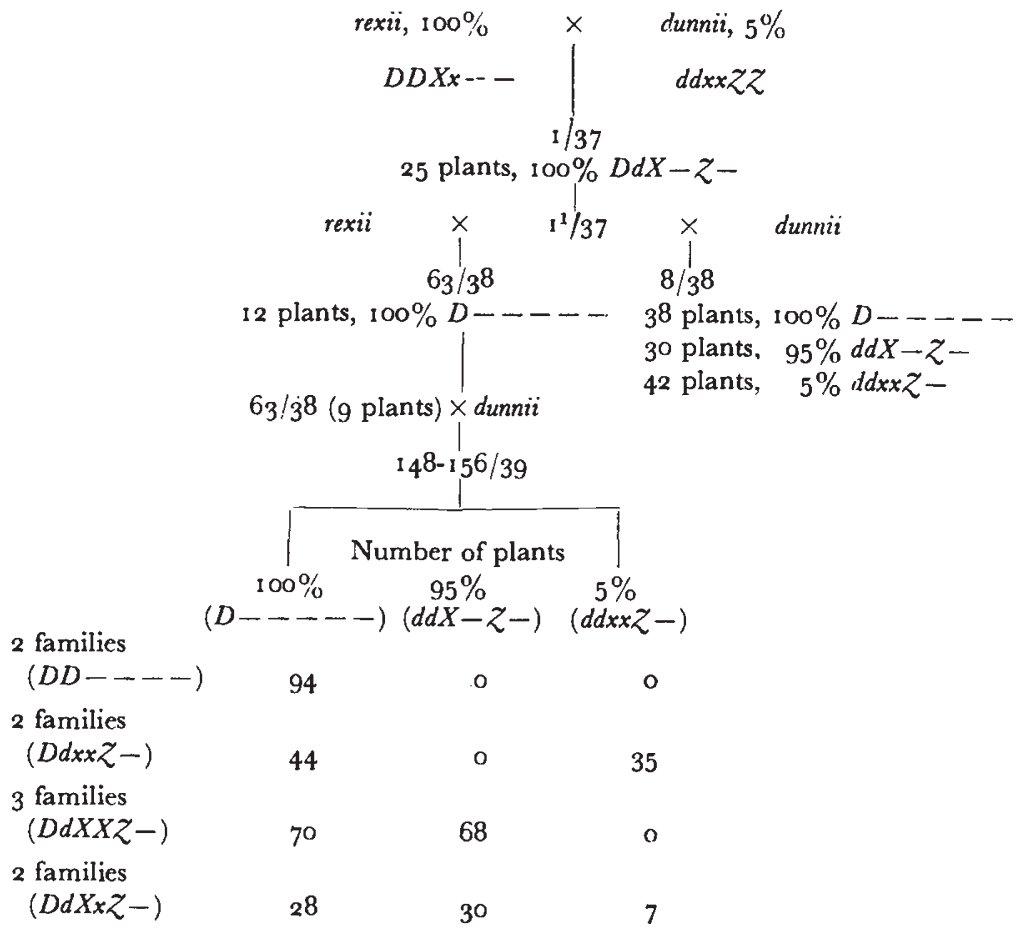


Further evidence is supplied by derivatives from rexii-dunnii crosses (table 9). The occurrence of the 95 per cent. dimonoside class in family $8 / 3^{8}$ shows that the plant of rexii used must carry an $X$ gene. Similarly, the occurrence of the 5 per cent. class in families I48I 56/39 shows that rexii must carry an $x$ gene, i.e. rexii is $X x$. rexii $L$

TABLE 10

Pedigree showing constitution of rexii for $\mathrm{Z}$

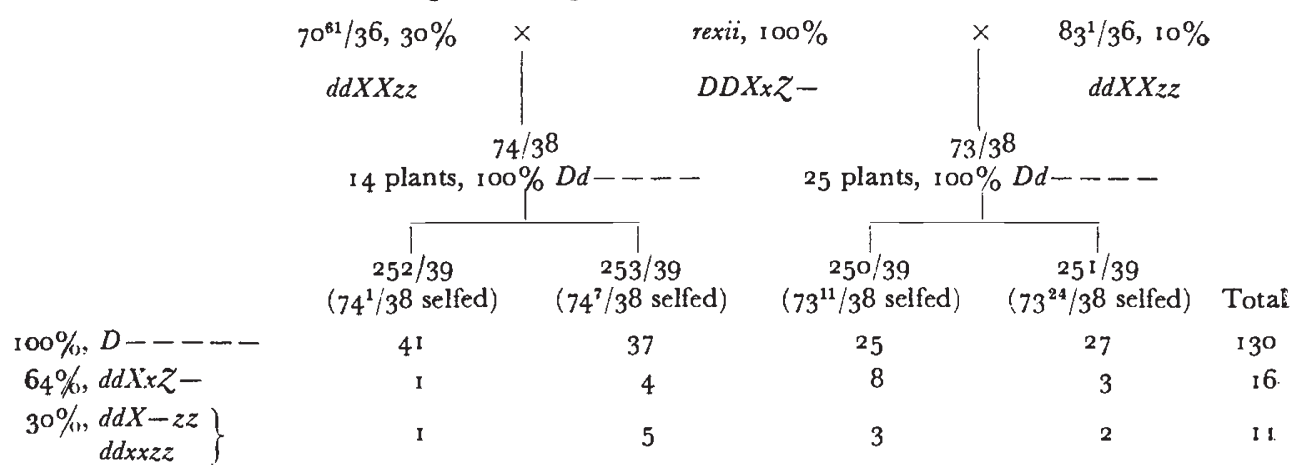

also was crossed to dunnii and a $\mathrm{B}_{1}$ raised by backcrossing to dunnii. The numbers of Ioo, 95 and 5 per cent. dimonoside progeny were 45, 30 and 33 respectively ( $c f$. table 9 , family $8 / 38$ ). Thus, rexii $L$, like rexii, may be presumed to be $X x$. rexii $L$ differs from rexii in a sufficient number of characters to suggest it should have the rank of a sub-species, if not species ; and its provenance is, apparently,

TABLE II

Inheritance of $\mathrm{Z}$

\begin{tabular}{|c|c|c|c|c|}
\hline \multirow{2}{*}{$\begin{array}{c}\mathrm{B}_{1} \text { parents }(O d) \\
\text { (see table Io) }\end{array}$} & \multicolumn{4}{|c|}{ Percentage dimonoside : class means } \\
\hline & $87 \cdot 5$ & $62 \cdot 5$ & $37 \cdot 5$ & $12 \cdot 5$ \\
\hline 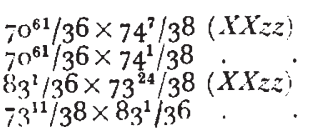 & $\begin{array}{r}22 \\
21 \\
5 \\
8\end{array}$ & $\begin{array}{l}2 \\
3 \\
0 \\
1\end{array}$ & $\begin{array}{l}5 \\
4 \\
1 \\
0\end{array}$ & 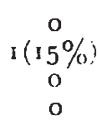 \\
\hline
\end{tabular}

highly limited. Therefore the occurrence of $x$ in both rexii and rexii $L$ suggests that this mutant is by no means rare in the wild.

The remaining evidence for the constitution of rexii came from crosses with two true breeding, low dimonoside varieties (table Io). The figures for $\mathrm{F}_{2}$ refer to $O(R) d$ genotypes only, since it is not possible to identify satisfactorily low and high dimonosides in ord forms. The values 64 per cent. and 30 per cent. in families 250-253/39 represent the averages of high and low dimonoside production forms respectively. The occurrence of the 64 per cent. class confirms that rexii carries $Z$, as do also the $B_{1}$ families (table I I). Although in table I I clear-cut 
segregation of low and high dimonosides is not evident as in tables 8 and 9 , it is, nevertheless, obvious that low dimonosides $(X-Z-)$ types occur. If rexii were $Z Z$ all $\mathrm{F}_{1}$ individuals would be $Z z$ and all should give a proportion of high dimonoside $X Z$ forms. But if rexii were $Z Z$ some of the $F_{1}$ plants should breed true for low dimonoside. Actually, none did so but as only four were tested it cannot be concluded that rexii is $Z Z$.

The behaviour of the garden forms can now be examined in the light of the above scheme. From tables 8 and 10 , we have seen that garden forms $70^{61} / 36,83^{1} / 3^{6}$ and $86^{13} / 37$ can be assigned the constitution $X X z z$. In addition, sixteen other garden forms were crossed with dunnii. Twelve of the $F_{1}$ 's comprised high dimonoside individuals only and the garden parents can be designated $X X-\ldots$. Three of

TABLE 12

Inheritance of 3-pentoseglycoside $(P G)$ and 3-monoside $(M O)$ in garden forms and in garden forms $\times$ dunnii

\begin{tabular}{|c|c|c|}
\hline Parents & No. of plants & Progeny \\
\hline $\begin{array}{l}\text { PG selfed } \\
\mathrm{PG} \times \mathrm{MO} \\
\mathrm{PG} \times \mathrm{PG}(\text { dunnii }) \\
\mathrm{MO} \times \mathrm{PG}(\text { dunnii }) \\
(\mathrm{MO} \times \mathrm{PG}(\text { dunnii })) \times \mathrm{MO} \\
\mathrm{MO} \times \mathrm{MO}\end{array}$ & $\begin{array}{r}12 \\
66 \\
27 \\
14 \\
8 \\
37\end{array}$ & $\begin{array}{l}\text { PG } \\
\text { PG } \\
\text { PG } \\
\text { PG } \\
\text { PG (?) } \\
\text { MO (and some PG (?)) }\end{array}$ \\
\hline
\end{tabular}

these twelve gave only low dimonosides when selfed and are, therefore, $X X z z$. The remaining four garden forms gave both high and low individuals in $\mathrm{F}_{1}$ with dunnii and so are $X x-\ldots$. Finally, one garden form that gave only high dimonosides when crossed to dunnii gave only high dimonosides when selfed: its constitution is, therefore, $X X Z Z$. No $x x Z Z$ garden forms have been identified from breeding. Thus all 19 of the garden forms crossed to dunnii carried $X$. This is not surprising since of $g^{I} d d$ individuals cxamined chemically, only two did not carry secondary dimonoside, i.e. the great majority must be presumed to be $X-Z-$.

(c) Pentoseglycoside and monoside. Ninety-two $d d$ garden forms were tested for their glycosides. Ninety contained a proportion of $3: 5$ dimonoside, the accompanying glycoside being 3-pentoseglycoside in 57 plants and 3-monoside in 33 plants. Two plants contained nothing but 3 -monoside. Therefore the genes controlling pentoseglycoside and monoside production are common in the garden forms and these sugars occur as alternatives.

Curtailment of these studies prevented our obtaining conclusive evidence on the inheritance of 3-pentoseglycoside and 3-monoside (table 12). The pentoseglycoside character appears to be dominant (or, more probably, epistatic) to the monoside. The simplest genetical explanation for these results would be that two pairs of genes are 
concerned such that $P(Q)$ produce pentoseglycoside and $p Q$ monoside. But the inheritance of monoside is not clear, monoside crossed monoside apparently giving pentoseglycoside as if, for example, complementary genes were involved in the production of pentoseglycoside. One situation, however, is plain. Some $X X z z$ garden forms contain goI oo per cent. monoside, others 90-Ioo per cent. pentoseglycoside, therefore the possibility that $X$ produces monoside and $Z$ pentoseglycoside can be rejected and the control of monoside and pentoseglycoside must be ascribed to other genes. For ease of discussion, we shall use the symbol $P$ to denote a gene, or genes, producing 3-pentoseglycoside and similarly $Q$ for monoside.

TABLE 13

Independent inheritance of $\mathrm{O}$ and $\mathrm{C}$

\begin{tabular}{|c|c|c|c|c|}
\hline \multirow{2}{*}{ Generation } & \multicolumn{4}{|c|}{ Genotype } \\
\hline & $O C$ & Oc & $n C$ & $o c$ \\
\hline $\mathrm{F}_{2}$ & $\begin{array}{ll} & 4^{2} \\
\text { Calc. } & 45\end{array}$ & $\begin{array}{l}17 \\
15\end{array}$ & $\begin{array}{l}17 \\
15\end{array}$ & $\begin{array}{l}4 \\
5\end{array}$ \\
\hline \multirow[t]{2}{*}{$\begin{array}{l}\mathrm{B}_{1} \\
\mathrm{~B}_{1} \\
\mathrm{~B}_{1} \\
\mathrm{~B}_{1}\end{array}$} & $\begin{array}{l}5 \\
9 \\
9 \\
9\end{array}$ & $\begin{array}{r}6 \\
12 \\
10 \\
10 \\
\end{array}$ & $\begin{array}{l}9 \\
6 \\
4 \\
6\end{array}$ & $\begin{array}{l}7 \\
7 \\
6 \\
7\end{array}$ \\
\hline & $\begin{array}{ll}\text { Total } & 32 \\
\text { Calc. } & 30.5\end{array}$ & $\begin{array}{l}38 \\
30 \cdot 5\end{array}$ & $\begin{array}{l}25 \\
30.5\end{array}$ & $\begin{array}{l}27 \\
30 \cdot 5\end{array}$ \\
\hline
\end{tabular}

(v) Linkage

No special study has been made of linkage between the pigmentproducing and modifying genes discussed in this paper. $F(A), O$, $R$ and $D$ were earlier shown to be independent, which is confirmed, and now independence is established for $V$ and $F$ (table 3 ). Segregation for $O$ and $C$ is given in table 13 and reveals the independent inheritance of these alleles. There is no linkage evidence regarding $X$ and $Z$. As will be shown in a subsequent paper, $F$ and $I$ are components of a complex-or super-gene and exhibit complete linkage in appropriate crosses, but this has no relevance for the present discussion.

\section{(vi) Interaction of pigment genes}

During the course of the experiments described in this paper, 133 parental garden forms (20 blue, 33 mauve, 17 magenta, 34 rose, 3 pink and 26 salmon) were tested chemically for their flower pigments. Until these tests were made, there was no means of knowing the proportion of dimonoside, pentoseglycoside or monoside in these plants or the degree of co-pigmentation. Thus, it would be legitimate to regard them as a fairly unbiased population from which samples 
could be taken for one purpose or another, e.g. to ascertain the degree of co-pigmentation or the proportions of the glycosides.

Plants were scored for the amounts of primary or secondary dimonoside, pentoseglycoside, monoside and cyanidin, also co-pigment and chlorogenic acid. The amounts of the glycosides were estimated in per cent. at intervals of 5 per cent. The other characters were classified into 4 arbitrary, but distinct, classes denoted by the values I Oo, 75, 50 and 25 per cent. with a fifth class, o per cent. The figure of roo per cent. does not necessarily indicate the maximum possible value but only that class which approaches, and includes, the maximum. Since the amount of $3: 5$-dimonoside found in $d d$ forms is less than 50 per cent. in 70 per cent. of cases, the percentage of individuals having 25 per cent. or more dimonoside was chosen as a convenient classification.

The actual method of comparison was to estimate penetrance and expressivity of the "dominant" genes concerned, in relation to the three anthocyanidin classes, $O R, o R$ and or representing the delphinidin, cyanidin and pelargonidin derivatives respectively. It could be argued that the terms penetrance and expressivity do not strictly apply to some of our data, since there is no conclusive proof that single genes control methylation and production of chlorogenic acid; and two complementary genes are responsible for secondary dimonoside production. The terms are convenient, however, and in any case the concept of a single gene being responsible for a given phenomenon is dependent on the degree to which genetic analysis itself has " penetrated ". Further, all, or the great majority, of the plants investigated carried the gene(s) producing a particular character, consequently, unless pigment suppression occurred through gene interaction, that character should have been manifest. The genetic constitution of all the plants investigated for primary dimonoside content was actually determined by breeding; all but two of the total number of plants scored for secondary dimonoside did, in fact, contain dimonoside and therefore carried both $X$ and $Z$; all plants but two were methylated and therefore can be postulated to carry $M ; c c$ individuals were a small minority; and all the plants scored for pentoseglycoside or monoside did in fact contain these glycosides and the population must therefore have carried the gene(s) governing pentoseglycoside and monoside production. In short, quantitative variation in the characters studied would result, in the main, from gene interaction and not gene segregation.

The analyses covered plants bred from I 934 to 1939 inclusive. To avoid drawing erronenus conclusions the data were examined for any shift in the frequency ot pigment types that might have occurred owing to unconscious genetic selection over this period. No trend of consequence was found except for co-pigmentation in the rose class $(o R d)$ subsequent to 1937 , consequently, only the I934-36 data were used throughout the $o R$ anthocyanidin class. 
Referring to the genetical constitution of the $O R$ class, 26 plants were known to be homozygous dominants $R R, 3$ were heterozygotes and $t$ were either homozygotes or heterozygotes. Thus any genetical variation in the $O R$ class would be mainly with respect to $O$, at least 70 per cent. of the plants being heterozygous for this gene. In the $o R$ class, at least 6o per cent. of the plants were $R R$. Since mixtures of malvidin and peonidin, or malvidin and pelargonidin or peonidin and pelargonidin have not been found in the garden forms, $O$ and $R$ may be assumed to be completely dominant or nearly so.

The results of the survey are given in table 14 which, while it must be taken to indicate trends only, brings to light interesting aspects of gene interaction in pigment production. The glycoside data refer to the occurrence or amount of mixed glycosides and each row involves a comparison between two types of sugar. Thus with primary $(D d)$ and secondary dimonoside, the comparison is between dimonoside on the one hand and pentoseglycoside or monoside on the other hand; with pentoseglycoside the comparison is between pentoseglycoside and monoside. Similarly with cyanidin the comparison is between this unmethylated pigment and a methylated one, i.e. between mixed anthocyanins. No comparison is possible with either of the anthoxanthins, the data indicating the occurrence or amount of one pigment only.

Complete penetrance was observed in $7 D D$ and $24 D d$ plants producing primary and secondary dimonoside respectively ; also for chlorogenic acid. Since segregation for chlorogenic acid has never been observed in Streptocarpus it is highly probable that for this character also, all the plants tested were homozygous dominants. In two other instances, viz. pentoseglycoside and co-pigment, penetrance varies with the nature of the anthocyanidin, being least in the or class and greatest in the $O R$. Thus in the case of pentoseglycoside, the percentage of the population carrying this sugar as opposed to monoside increases or $\angle O R$; although no similar comparison (mixed pigments) arises with co-pigment, there is a similar increase in penetrance from $o r<O R$. In short, $D, X Z, P$ and $C$ can be said to interact quantitatively, each in the same way, with $O$ and $R$. On visual assessment we had described $D$ as being completely dominant, i.e. $D d$ plants are conspicuously bluer than $d d$ and it is not possible to distinguish heterozygotes from dominant homozygotes. On chemical assessment, dominance is not always complete in $D d$ heterozygotes, the proportion of plants showing complete dominance being 9o, 75 and 50 per cent. respectively in the $O R, O R$ and or classes. A similar situation has been reported in Antirrhinum (Jorgensen and Geissman, 1955).

Summing the data for $D$ (in $D d$ plants), $X Z, P$ and $C$ it is found that the effect of $o R$ on penetrance, compared with that of or, is approximately the same as that of $O R$ compared with $o R$. These incremental effects must be ascribed, in the main, to the presence 
or absence of $O$ and of $R$, since comparison of homozygotes with heterozygotes reveals no correlation with penetrance, i.e. dominance of $O$ and $R$ is complete or nearly so.

Considered as a whole (but excluding cyanidin for the moment), the data in table I4 suggest that penetrance is (I) complete when the gene concerned is in the homozygous dominant phase, (2) incomplete in the heterozygous phase, (3) dependent in degree on the genetical background with respect to $O$ and $R$; and (4) the incremental effects of $R$ and $O$ on penetrance are approximately equal and supplementary.

T.ABLE I 4

Gene interaction in pigment production

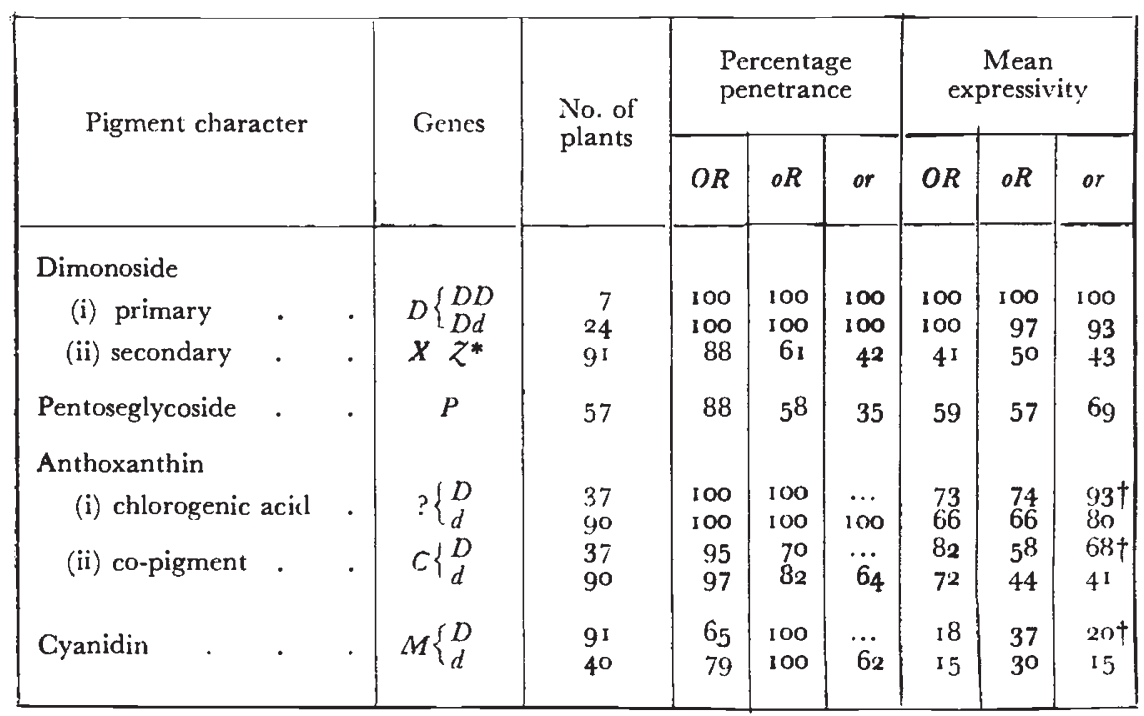

* Percentage of plants with more than 25 per cent. dimonoside.

t Only three plants.

Turning to expressivity in general the degree of expressivity is lower than the degree of penetrance, complete expression is found only in $D D$ plants, and no consistent gradation is to be seen between anthocyanidin classes. However, while the glycosides exhibit no great differences between anthocyanidin classes, the anthoxanthins, especially co-pigment, do and, further, expressivity seems to vary with the genetic constitution for $D$ and $d$, i.e. there is correlation in the production of co-pigment and diglycoside and $C$ interacts with $D$ and $X Z$. The fact that penetrance grades $O R>$ or, but expressivity does not, probably means that the differences in degree of penetrance stem from differences in the threshold for production of a precursor necessary for the synthesis of anthocyanin.

The results with cyanidin require special consideration. Although all but two of the garden forms contained methylated anthocyanins and gave methylated progeny, i.e. they bred true for $M$, the unmethylated pigment, cyanidin, often accompanies, usually in small 
amount, the methylated anthocyanins malvidin and peonidin, also pelargonidin. For example, in $d d$ plants the percentage frequency of the classes $0,25,50,75$ and 100 per cent. pigment (p. 316) is respectively $28,62,7 \cdot 0,2 \cdot 7$ and 0.9 . In $d d$ plants, penetrance is complete in the $O R$ class but not in $O R$ and or; and similarly expressivity is relatively high in the same class, i.e. $o R$ plants produce on average twice as much cyanidin as $O R$ or $o r$. Results for expressivity in the presence of $D$ appear closely to resemble those with $d d$ forms.

Further light is thrown on gene interaction involving cyanidin production by considering its association with the glycosides. In table I5, groups $(b)$ and $(d)$ might be termed "expectation" on the basis of the garden forms being homozygous for $M$. Groups $(e)$ and $(f)$ are manifest examples of interaction since cyanidin is found associated with one glycoside type but not the other. The majority

TABLE I5

\begin{tabular}{|c|c|c|c|}
\hline \multirow{2}{*}{ Genotype } & No. of plants & \multicolumn{2}{|c|}{ Cyanidin present with : } \\
\cline { 3 - 4 } & & Dimonoside & $\begin{array}{c}\text { Pentoseglycoside } \\
\text { or monoside }\end{array}$ \\
\hline$D-$ & 33 & $\begin{array}{l}(a)+ \\
(b) \pm(O R)\end{array}$ & \\
\hline 7 & $\begin{array}{c}(c)+ \\
(d) \pm \\
(e)+(o r)\end{array}$ & $\begin{array}{l} \pm \\
(f) \pm(140-, 4 \text { or })\end{array}$ \\
\hline
\end{tabular}

of plants fall into groups $(a)$ and $(c)$ and in these interaction is not, in the first place, between the genes controlling cyanidin and glycoside, but between those controlling cyanidin production and anthocyanidin type, as clearly seen from table i 4 . Nevertheless, analysis of group $(c)$ shows that whereas in or and $O R$ types the ratio of cyanidin accompanying dimonoside and non-dimonoside fractions is approximately $I: I$, in the $o R$ group it is $I \cdot 0: I \cdot 6$, i.e. more cyanidin accompanies the non-dimonoside than the dimonoside pigments or, conversely, methylation (or methoxylation) is correlated with dimonoside production and $M$ interacts with $X Z$.

Correlation between methylation and glycoside type was also observed in four comparable sibs, two ORd and two oRd, (rexii $\times$ dunnii) $\times$ dunnii containing mixtures of methylated and unmethylated pigments, table 16 . Methylation in both peonidin and malvidin derivatives was more complete in the dimonoside fraction than in the pentoseglycoside, i.e. $M$ interacts with $D$.

Correlation between methylation and glycoside type can also be secn by taking, separately, the pentoseglycoside and monoside fractions 
and noting the numbers of completely methylated individuals (table I 7 ). The figures for $37 D$ forms are also included in the table which shows that $M$ interacts with both $D$ and with $P$.

Finally, correlation between methylation and anthocyanidin type was demonstrated by counting the number of plants containing more

TABLE 16

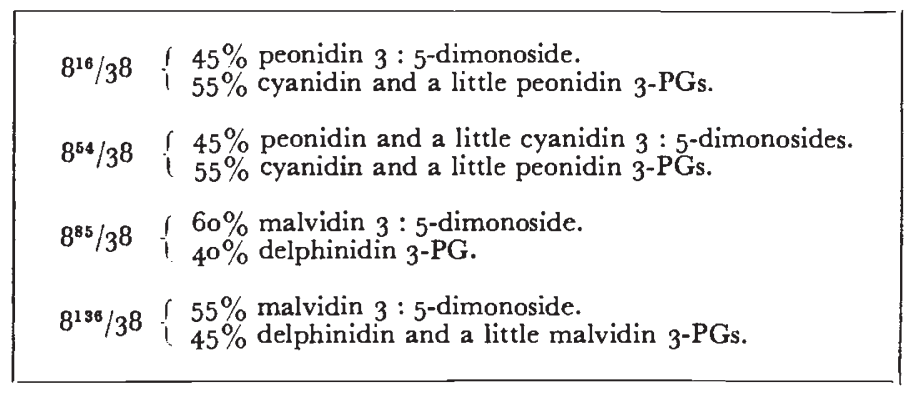

methylated pigment in the dimonoside fraction than in the nondimonoside, the percentage of such individuals in the $O R d$, oRd and ord classes being 72, 62 and 25 respectively, i.e. $M$ interacts with $O$ and $R$ and with $D$.

So much for the anthocyanins. Interaction is also manifest with the anthoxanthins as can be seen by comparing the amounts of chlorogenic acid and co-pigment produced in $F F$ (deep cyanic) and $F f$

TABLE 17

Correlation of methylation and glycosidation

\begin{tabular}{|c|c|c|}
\hline \multirow{2}{*}{ Glycoside type } & \multicolumn{2}{|c|}{$\begin{array}{l}\text { Percentage individuals } \\
\text { completely methylated }\end{array}$} \\
\hline & $O(R) d$ & $o R d$ \\
\hline Dimonoside $D$. & 64 & 2 \\
\hline Pentoseglycoside $(d)$ & 24 & o \\
\hline Monoside $(d)$ & o & o \\
\hline
\end{tabular}

(paler cyanic) classes. The results are given in table 18 , the lower half of which also includes the mean amounts for $R R$ and $R r$ individuals, distinguishing between $F F$ and $F f$ genotypes. The action of $F$ is known to be cumulative (p. 305) hence the table shows clearly that with increase in the amount of anthocyanin in $F F$ compared with Ff plants there is decrease of both anthoxanthins, i.e. $C$ and the genes controlling anthoxanthin production both interact with $F$.

It is probably significant that whereas there is no marked decrease in the amount of chlorogenic acid with increase in the number of 
recessive genes (column $\mathrm{I}$ ), there is a striking decrease in the amount of co-pigment. This suggests that the gene(s) controlling production of chlorogenic acid operates at an earlier stage of synthesis than does the gene controlling production of co-pigment.

The data referring to $R$ are of note. They show that interaction occurs between $R, F, C$ and the gene(s) controlling the production of chlorogenic acid. Less chlorogenic acid is produced in $F F$ flowers than $F f$ and, superimposed on this, less in $R R$ flowers than $R r$. This multiple competition is even more pronounced in the case of copigment. Assuming that decrease in the amount of anthoxanthin is

TABLE 18

Interaction of anthocyanins and anthoxanthins

\begin{tabular}{|c|c|c|c|c|c|c|c|c|c|}
\hline \multirow{2}{*}{$\begin{array}{l}\text { Genotypic } \\
\text { class }\end{array}$} & \multirow{2}{*}{$\begin{array}{l}\text { No. of } \\
\text { plants }\end{array}$} & \multicolumn{4}{|c|}{$\begin{array}{l}\text { Chlorogenic acid } \\
\text { mean amount per cent. }\end{array}$} & \multicolumn{4}{|c|}{$\begin{array}{c}\text { Co-pigment } \\
\text { mean amount per cent. }\end{array}$} \\
\hline & & $F F$ & $F f$ & & nd $F f$ & $F F$ & Ff & & \\
\hline \multirow[t]{3}{*}{$\begin{array}{l}O(R) D \\
O(R) d \\
o R D \\
\text { oRd } \\
\text { ord }\end{array}$} & $\begin{array}{r}8 \\
31 \\
14 \\
28 \\
21\end{array}$ & $\begin{array}{l}81 \\
62 \\
63 \\
65 \\
75\end{array}$ & $\begin{array}{l}88 \\
73 \\
88 \\
63 \\
86\end{array}$ & & $\begin{array}{l}35 \\
67 \\
73 \\
65 \\
31\end{array}$ & $\begin{array}{r}100 \\
63 \\
28 \\
33 \\
23\end{array}$ & $\begin{array}{l}94 \\
82 \\
50 \\
47 \\
32\end{array}$ & & \\
\hline & & \multicolumn{2}{|c|}{$F F$} & \multicolumn{2}{|c|}{ If } & \multicolumn{2}{|c|}{$F F$} & \multicolumn{2}{|c|}{$F f$} \\
\hline & & $R R$ & $R r$ & $R R$ & $R r$ & $R R$ & $R r$ & $R R$ & Rr \\
\hline$o D$ and $o d$ & 40 & 62 & 68 & 71 & 84 & 28 & $4^{I}$ & 40 & $6 j$ \\
\hline
\end{tabular}

the result of increase in the amount of anthocyanidin; and that both anthoxanthin and anthocyanidin are synthesised from a common substrate or precursor, then these results show that $R$ increases the amount of anthocyanidin produced by $F$. But the apparent effect of $R$ is to add a hydroxyl at position $3^{\prime}-$. Therefore the synthetic process that leads to increase in hydroxylation is closely associated with a process that leads to increase in the amount of precursor. Moreover since more anthocyanidin is produced in $R R$ than $R r$ flowers ; and since $R$ is completely dominant or nearly so, then in single dose it controls a reaction at an upper limit of its curve of effectiveness (Muller, 1932), especially in $F F$ plants, both in respect of the amount of anthocyanidin and its kind, peonidin (or cyanidin). In other words, from the adaptive point of view, $R$ has a high " factor of safety" (Haldane, 1939).

Owing to lack of the requisite genotypes no similar study could be made with $O$ (malvidin) but since this gene is completely dominant, and having regard to the results given in table 14 , it is probable that $O$, like $R$, is a hypermorph. 
Summarising the evidence on gene interaction in pigment production in the garden Streptocarpus, it appears that :-

(I) Penetrance of $D, X Z, P$ and $C$ increases with increase in the number of loci controlling hydroxylation at which dominant genes are present, thus : or $\angle O R<O R$ the incremental effects of $R$ and $O$ being approximately equal.

(2) Expressivity of $D, X Z, P$ and $C$ reveals no such proportionality but expressivity of $C$ is seemingly higher in $D$ than $d$ plants.

(3) Penetrance and expressivity of cyanidin is greater in $O R$ than $O R$ and or genotypes.

(4) Interaction occurs between $O$ (also $R$ ) and $D, X Z, P, M$ and $C$; between $M$ and $D, X Z$ and $P$; between $C$ and $F, D$ and $X Z$; and between the gene(s) for chlorogenic acid and $F$ and $R$.

(5) The main effects of these interactions on the chemical phenotype are :-

(i) increase in the number of hydroxyl groups in the B-ring is correlated with increase in methylation, also with increase in the number of sugars at positions 3 and 5 (monoside $\rightarrow$ pentoseglycoside $\rightarrow$ dimonoside).

(ii) increase in the aggregate number of the dominant genes $O, R$ and $D$ is associated with increase in apigenin production.

(iii) increase in anthocyanin production is correlated with decrease in anthoxanthin production.

\section{GENETICS OF SPECIES}

(i) Flower pigments

(a) Species. The data for the chemistry and genetics of flower colour in the garden forms have been given in the previous pages. We have now to see whether these facts throw any light on pigmentation and inheritance in the species and species hybrids.

More than 45 forms of Eustreptocarpus have been accorded specific rank by taxonomists. Of these, the authors have grown 27, viz. 2I with bluish flowers, I with brick-red (dunnii), I with cream (vandeleuri), and 4 with white flowers (parviflorus, pusillus, umtaliensis, B. L. Burtt, and wilmsii, Engler). The anthocyanins identified are listed in table rg.

Thirteen of the sixteen species tested chemically are pigmented by malvidin $3: 5$-dimonoside, one (meyeri) by delphinidin $3: 5$-dimonoside, and one (dunnii) by cyanidin 3-pentoseglycoside. The anthocyanins are the same as those found in the garden forms, and segregates derived from crosses between the species and the garden forms give the expected flower colours and pigments. We may assume therefore that the major genes controlling flower pigmentation in the species are homologous with those in the garden forms, i.e. I 5 of the 16 species carry $O,{ }_{15} D$, I $_{4} M$ and I od.

The species listed in table I 9 are all $O D$ genotypes except dunnii 
which is od. parviflorus, gracilis, comptonii and galpinii also are $O D$ and vandeleuri $o D$, a grand total of I9 $O D M$, I $O D m$, I $o D M$ and I $o d m$. In addition, one plant of parifiorus proved to be $O d$.

TABLE 19

\begin{tabular}{|c|c|c|}
\hline $\begin{array}{l}\text { Antho- } \\
\text { cyanin } \\
\text { class }\end{array}$ & Species & Anthocyanin pigment \\
\hline 1 & $\begin{array}{l}\text { cyaneus, S. Moore, daviesii, C. B. } \\
\text { Clarke, galpinii, Hook fil., gardeni, } \\
\text { Hook, grandis, N. E. Brown, insignis, } \\
\text { B. L. Burtt, michelmorei, B. L. Burt, } \\
\text { polackii, B. L. Burtt, wendlandii, } \\
\text { Sprenger }\end{array}$ & Malvidin $3: 5$-dimonoside \\
\hline 2 & rexii, Hook & $\begin{array}{l}\text { Malvidin } 3: 5 \text {-dimonoside }+ \text { trace } \\
\text { cyanidin dimonoside }\end{array}$ \\
\hline 3 & $\begin{array}{l}\text { gracilis, B. L. Burtt, haygarthii, N. D. } \\
\text { Brown, johannis, L. L. Britten, } \\
\text { polyanthus, Hook }\end{array}$ & $\begin{array}{l}\text { Malvidin } 3: 5 \text {-dimonoside }+ \text { some } \\
\text { petunidin and/or delphinidin }\end{array}$ \\
\hline 4 & meyeri, B. L. Burtt & $\begin{array}{l}\text { Delphinidin } 3: 5 \text {-dimonoside (+ possibly } \\
\text { some petunidin })+ \text { cyanidin } 3: 5^{-} \\
\text {dimonoside }\end{array}$ \\
\hline 5 & dunnii, Mast. & $\begin{array}{l}\text { Cyanidin } 3 \text {-pentoseglycoside }+5-10 \% \\
\text { cyanidin } 3 \text {-bioside }\end{array}$ \\
\hline
\end{tabular}

The fourth of the main pairs of alleles governing anthocyanin pigmentation is $R r$. Since $O$ is epistatic to $R$, the distribution of the latter gene among the species cannot be directly determined. Crosses were therefore made between 18 species and 4 wild varieties on the

TABLE 20

Distribution of $\mathrm{R}, \mathrm{r}$ in Streptocarpus

\begin{tabular}{|c|c|c|}
\hline Species & $R-$ & $r r$ \\
\hline cyanic & $\begin{array}{c}\text { gardeni, meyeri, johannis, polyanthus, } \\
\text { haygarthii, grandis, wendlandii, dunnii, } \\
\text { michelmorei, eylesii, B. L. Burtt }\end{array}$ & $\begin{array}{c}\text { rexii, rexii L, insignis, cyaneus, polackii, } \\
\text { montigena }\end{array}$ \\
\hline acyanic & $\begin{array}{c}\text { parviftorus, Hook *, vandeleuri, E. G. } \\
\text { Bak and S. Moore }\end{array}$ & meyerii var. rexii $S$, rexii B, rexii FB \\
\hline
\end{tabular}

* parviforus, Hook is incorrectly given as parviflorus, E. Meyer in Lawrence et al. 1939 .

one hand, and ord garden forms on the other. $R$ or $r$ forms were then extracted by backcrossing and identified chemically (table 20). Twelve species carry $R$ and six $r$. Five of these six are members of what, with respect to the general morphology of flowers and foliage, we shall call the rexii group. This group is identified by morphochemical characteristics and, as will be shown in a later paper, by 
its geographical distribution. Three white-flowered varieties of rexii from the wild also are $r$. Although $R$ is hypostatic to $O$, it appears to have an adaptive advantage since it is carried by the majority of the species cxamined.

It is of interest that in gracilis, haygarthii, johannis, and polyanthus, species having distinct cornucopea-shaped flowers, methylation is not complete and the anthocyanins are therefore mixtures of malvidin, petunidin and/or delphinidin dimonosides. Here again is a natural group identified by morpho-chemical and geographical characteristics.

(b) Species hybrids. Thirty-three hybrids involving twelve species have been examined for their anthocyanin pigments. The results are summarised as follows :--

(I) In 9 cases where class I parents (completely methylated) were crossed together, all the hybrids were completely methylated.

(2) In 13 cases where class I parents were crossed with class 2, 3 or 4 parents (incompletely methylated), ro hybrids were completely and 3 incompletely methylated.

(3) In 9 cases where class I parents (complete oxidation) were crossed with class 2 or 4 parents (incomplete oxidation), 7 of the hybrids showed complete and 2 incomplete oxidation.

(4) In 6 cases where class I parents were crossed with class 5 (incomplete oxidation and methylation), 5 hybrids showed incomplete and $\mathrm{r}$ complete oxidation and methylation.

(5) dunnii (class 5) $\times$ michelmorei (class I) gave hybrids containing diglycoside and pentoseglycoside.

Referring to the species pigmented mainly by malvidin, it is clear that those anthocyanin characters occurring most frequently in the genus, namely complete oxidation and methylation, tend to be completely dominant in inheritance. This is evident in the hybrids with dunnii (malvidin $\times$ cyanidin) where, though there is a moderate amount of cyanidin, the main pigment is completely oxidised and methylated.

\section{(ii) Stem and leaf pigments}

Six wild forms, viz. rexii, gardeni, montigena, johannis, grandis and grandis albus, also two artificial hybrids derived from grandis and dunnii respectively, have been found by our colleague, Dr J. B. Harborne, to contain one main pigment in their peduncles. rexii, montigena and the dunnii hybrid carried this same pigment in their leaf tips. From chromatographic and spectral studies, it was established that the pigment was an unacylated cyanidin glycoside. It was, however, different from any of the known cyanidin glycosides, and, on acid hydrolysis, gave the sugars, glucose and xylose. On partial acid hydrolysis the pigment gave rise to cyanidin 3 -glucoside. It appears from these results that the pigment is cyanidin 3 -xyloglucoside.

The authors had previously used Robinson's methods to identify 
the stem pigment in other species. In rexii $B$, gracilis, comptonii and the acyanic species kentaniensis, Britten and Storey, and umtaliensis, the main pigment was a cyanidin glycoside. Twelve $\mathrm{B}_{1}$ plants from (rexii $\times$ dunnii) $\times$ dunnii also contained the cyanidin glycoside. In the hybrid, johannis $\times$ wendlandii a mixture of cyanidin monoside and the glycoside was found in both stems and leaves, and this mixture was carried by the deeply pigmented leaves of wendlandii. Thus, in every species examined the stem pigment is cyanidin, presumably present as the previously mentioned 3-xyloglucoside.

The fact that unmethylated anthocyanidin is found in the stems of a number of species whose flowers carry methylated pigment, means that $M$ acts only in the flowers. A somewhat similar situation is seen in wendlandii where $D$, producing $3: 5$-dimonoside, is completely dominant in the flowers but not in the leaves where monoside appears to predominate. Again, in $D$ plants, $3: 5$-dimonoside is produced in the flowers but the cyanidin glycoside is produced in the flower stems. Thus, $D$ also acts only in the flowers.

\section{(iii) Pigment inheritance}

In section (i) evidence was presented respecting the constitution of various species for the genes $O, R$ and $D$ determining specific anthocyanidin pigmentation. In this section breeding results will be given for $F$.

parviflorus and $1 / 33$, both VVffii, were crossed to a natural whiteflowered variety of meyeri here styled meyeri albus, and to pusillus, wilmsii and grandis albus, I combinations in all. None of these gave cyanic progeny, therefore all are $f f$. meyeri albus, wilmsii and grandis albus have coloured flower stems and are presumably VVff. pusillus has green stems and may be voff. Three acyanic varieties of rexii were tested : rexii $S$ and rexii $B$ are $V V f f$ and rexii $F B$ voFF. Since rexii is $V V F F$, all three of the possible homozygous dominant combinations are shown to occur in the wild.

The inheritance of $F$ and especially, $f$, was also studied in five series of crosses. Table 2 I compares, in summary, the breeding behaviour of rexii and its varieties in intra- and inter-specific crosses and in reciprocal crosses with species and garden forms.

Inter-specific crosses give normal ratios for mono-factorial inheritance (series $1 a, 3$ and $4 a$ ) but in intra-specific crosses (series $5 a$ and $b$ ) there is a great deficiency of recessives $\left(F_{2}, 26: I ; B_{1}, 4: I\right)$. An additional comparison can be made between what we may call interand intra-group crosses. Thus most of the cyanic species used in series $\mathrm{I} b$ and 3 belong to the rexii group and these, when crossed to acyanic garden forms (equivalent to inter-group crossing) give normal $3:$ I ratios (series 3 ), unlike the intra-group crosses with rexii $S$ (series $\mathrm{I} b$ ) where the ratio is $3.6: \mathrm{I}$ and significantly aberrant. A similar situation is found between the inter-and intra-group $\mathrm{F}_{2}$ 's in 
series $4^{a}$ where the ratio is $3: \mathrm{I}$ and $4^{b}$ where it is $6: \mathrm{I}$ (though the $\mathrm{B}_{1}$ in $4^{c}$ is normal) ; and also between series $\mathrm{I} a$, ratio $3^{\circ} \mathrm{o}: \mathrm{I}$ and $\mathrm{I} b$, ratio $3.6: 1$. Finally, a clear-cut difference is secn between acyanic

TABLE 21

Inheritance of $\mathrm{F}, \mathrm{f}$ in species crosses

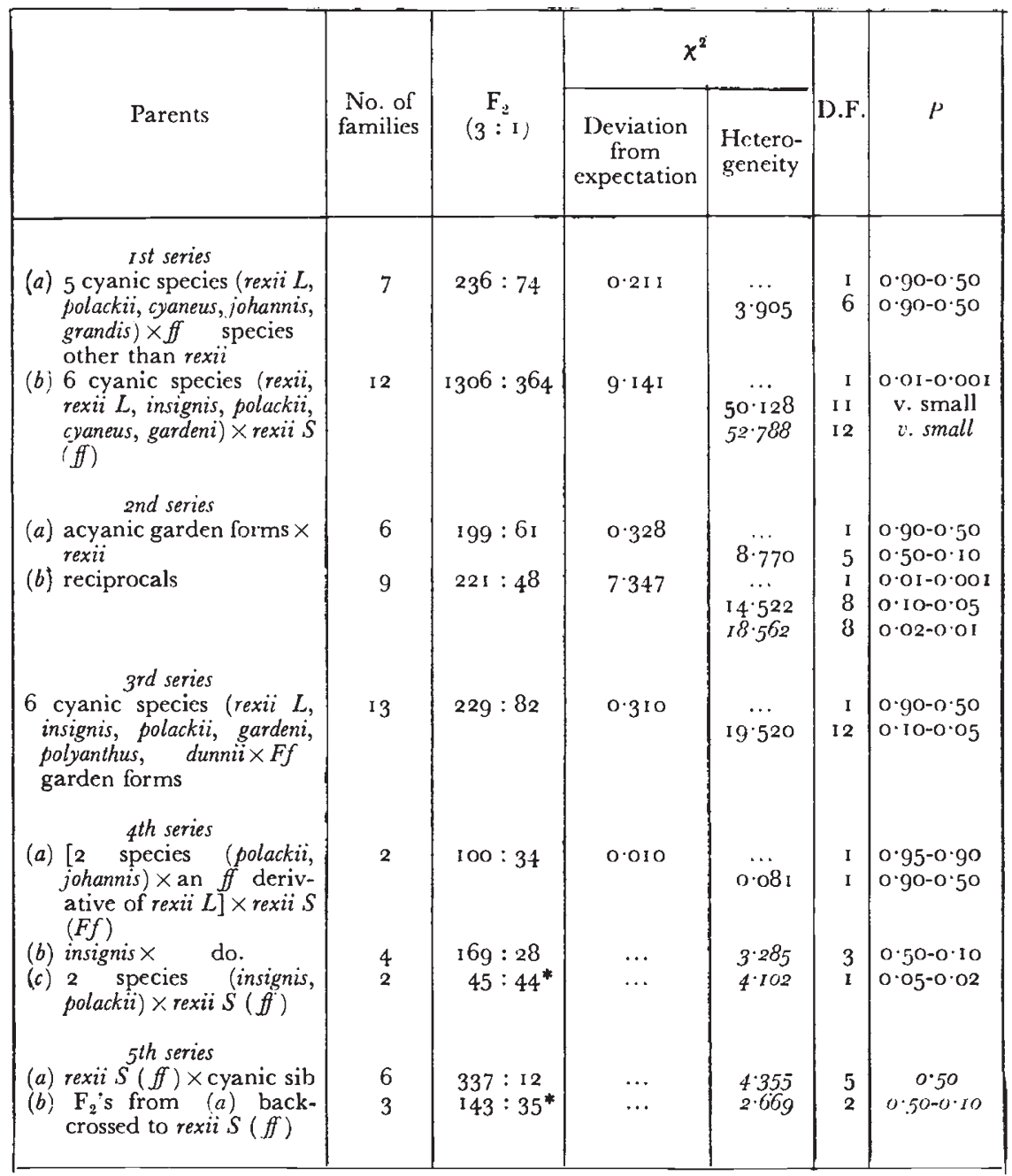

$*=\mathrm{B}_{1}$.

italics $=$ calculated on the actual ratios observed, i.e. not on $3: \mathrm{I}$ or $1: \mathrm{I}$.

garden forms crossed to rexii $(2 a)$ and the reciprocals $(2 b)$, the respective $\mathrm{F}_{2}$ ratios being $3 \cdot 3: \mathrm{I}$ and $4 \cdot 6: \mathrm{I}$.

If, in this series of crosses, cyanics are presumed to be $V F i$ and acyanics $V f$, then the segregation of $f$ in $\mathrm{F}_{2}$ is (I) normal when cyanic species other than rexii are crossed with garden forms or with acyanic species other than rexii varieties, (2) abnormal when rexii is used as 
the female, but not male, parent, and (3) greatly abnormal in crosses between cyanic and acyanic varieties and progeny of rexii.

The reciprocal difference seen in the $\mathrm{F}_{2}$ 's in $2(a)$ and $(b)$, table $2 \mathrm{I}$, could be a cytoplasmic effect, in which $f f$ zygotes are fully viable with garden-form cytoplasm but often inviable with that of rexii. Alternatively, certation would fit the results if we suppose $f$ pollen-tubes grow at the normal rate in the styles of plants having garden-form cytoplasm but much slower in styles of plants with cytoplasm derived from rexii. An analogous case has been reported in crosses between Enothera pallida and O. trichocalyx (Crowe, 1955) where it was found that it was the cytoplasm in the pollen which controlled the growth rate of the various pollen genotypes and the proportions of the $F_{2}$ segregates. Certation is common in the rexii group of species, as will be shown in a later paper, therefore it is more likely that the reciprocal differences discussed above are an expression of certation rather than of differential zygotic lethality.

In the fifth series, where the crosses are all within the one species, rexii, certation would be expected to exhibit its greatest effect, even in the absence of cytoplasmic influences. Whatever the particular mechanism that leads to the deficiency of $f$ genotypes (note, the percentage deficiency is of the same order in both $F_{2}$ and $B_{1}$ ), it is clear that rexii carries a factor, or factors, which strongly favour the survival of cyanic $(F)$ genotypes, a feature which is probably shared by rexii varieties and perhaps also by closely related species in the rexii group. Observations on Streptocarpus in the wild support this view. "The coloured flowers bloom in profusion in our forest patches, and I think one could expect to find (only) one or two white-flowered plants in any 500 acres where the others occur." (Storey, I 953).

A general conclusion from these studies on flower colour and its inheritance in the species is that a very high percentage of cyanic phenotypes is maintained in the wild population by adjustment of their nuclear and cytoplasmic balance.

\section{DISCUSSION}

\section{(i) Flower pigments}

Nine pairs of alleles controlling flower colour in Streptocarpus have been identified, each with a distinct phenotype and each exhibiting Mendelian inheritance. In these respects it is probable that, had selection of our material continued a little longer, a tenth factor, $M$, could have been included with the other nine. An eleventh factor, $P$, is suspected. The phenotypic effects of all these genes is summarised in table 22. Alleles similar in effect to $F, I, C$ and $R$ have been reported for various species (Scott-Moncrieff, I936, I939; Geissmann et al., I954).

The circumstances relating to the independent inheritance of $O$ and $R$ and epistasy of $O(O R$ and $O r$ giving delphinidin, $o R$ cyanidin 
and or pelargonidin derivatives) have been reported for only one other species, Lathyrus odoratus (Beale et al., 1939). In Lathyrus interspecific hybridisation has not, apparently, been involved, the wild type being a delphinidin derivative, whereas in Streptocarpus the alleles $O O, r r$ are derived from rexii and the oo, $R R$ from dunnii. Although no cyanidin types occur in Primula sinensis it too could be considered along with Streptocarpus since $K$ individuals contain malvidin and $k$ pelargonidin, i.e. $K$ is homologous to $O$ in Streptocarpus in giving,

TABLE 22

Gene syndrome controlling pigment production and modification in flowers of Streptocarpus

\begin{tabular}{|c|c|c|}
\hline Gene & $\begin{array}{l}\text { General } \\
\text { function }\end{array}$ & Phenotypic effect \\
\hline V & $\begin{array}{l}\text { Pigment } \\
\text { production }\end{array}$ & $\begin{array}{l}\text { (i) produces cyanidin } 3 \text {-xyloglucoside in flower stems. } \\
\text { (ii) produces delphinidin or cyanidin or pelargonidin in } \\
\text { throat lines }(L) \text { and unidentified anthocyanidin in } \\
\text { capitate pistillar hairs }(B) \text {, i.e. production in limited } \\
\text { areas. }\end{array}$ \\
\hline$F$ & " & $\begin{array}{l}\text { in presence of } V \text {, produces delphinidin, cyanidin or pelar- } \\
\text { gonidin in whole corolla, i.e. production in unlimited area. }\end{array}$ \\
\hline $\begin{array}{l}I \\
C\end{array}$ & ", & $\begin{array}{l}\text { increases amount of anthocyanidin in flowers. } \\
\text { produces co-pigment (probably apigenin) in flowers. }\end{array}$ \\
\hline$R$ & $\begin{array}{l}\text { Pigment } \\
\text { modification }\end{array}$ & $\begin{array}{l}\text { gives hydroxyl groups in the } 3^{\prime} \text { and } 4^{\prime} \text { positions on the side } \\
\text { ring instead of only in the } 4^{\prime} \text { position }(r) \text {. }\end{array}$ \\
\hline$O$ & ", & $\begin{array}{l}\text { gives hydroxyl groups in the } 3^{\prime}, 4^{\prime} \text { and } 5^{\prime} \text { positions instead } \\
\text { of only in the } 4^{\prime} \text { position }(o r) \text {. }\end{array}$ \\
\hline$D$ & " & $\begin{array}{l}\text { gives large amount of } 3: 5 \text {-dimonoside in place of mixture } \\
\text { of } 3: 5 \text {-dimonoside and } 3 \text {-pentoseglycoside, or monoside } \\
(d) \text {. }\end{array}$ \\
\hline$x, z$ & ," & $\begin{array}{l}\text { complementary for production of limited amount of } 3: 5 \text { - } \\
\text { dimonoside in place of } 3 \text {-pentoseglycoside or } 3 \text {-monoside } \\
(x Z, X z \text { and } ? x z) \text {. }\end{array}$ \\
\hline $\begin{array}{l}M ? \\
P ?\end{array}$ & " & $\begin{array}{l}\text { methylates hydroxyl groups. } \\
\text { controls 3-pentoseglycoside production. }\end{array}$ \\
\hline$Q ?$ & " & controls 3 -monoside production. \\
\hline
\end{tabular}

apparently in one step, the $3^{\prime}, 4^{\prime}, 5^{\prime}$-trihydroxy structure in place of the $4^{\prime}$-monohydroxy one.

Turning now to the inheritance of glycoside, we have established that incomplete dominance of $3: 5$-dimonoside is sometimes found in $D d$ heterozygotes, and always in $d d X-Z-$ individuals, the minor component of the mixed glycosides being either 3-pentoseglycoside or 3 -monoside according to the genotypic constitution of the plant for the genes controlling these types. Although these genes have not been identified, it seems that the one (or ones) controlling pentoseglycoside production $(P)$ will be found to be epistatic to that controlling monoside $(Q)$. The glycosides would then fall into an ascending epistatic series: monoside $(Q)$ pentoseglycoside $(P)$, secondary dimonoside $(X, Z)$ primary dimonoside $(D)$, in a manner similar to the anthocyanidin series, pelargonidin $(o r)$, cyanidin $(o R)$ and delphinidin $(O R)$. 
(ii) Stem pigments

At first sight, $V$ produces only cyanidin in the stems but any one of the three anthocyanidin derivatives in the flower lines, and possibly in the pistillar hairs, of $V f$ flowers. However, in widely different species, species hybrids and garden forms, the stem anthocyanin has been identified as cyanidin 3-xyloglucoside, whether the flowers are cyanic $V F$, or acyanic $V f$, and regardless of the presence or absence of the genes controlling hydroxylation, methylation and glycosidation of the anthocyanidin in the corolla (as distinct from the throat lines). Hence, $O_{0}, R r, M m$, $d d$ and (possibly) $D$, modify the anthocyanidin in the flowers but not in the stems. And the basic effect of $V$ must be the control of a precursor necessary for the production of anthocyanidin in flowers, stems and leaves. The action of $F$, then, is to extend the area of general cyanic pigmentation from the lines and hairs to the whole of the flower. In view of the diverse kinds of Streptocarpus to which the above facts apply, it is highly probable that they are universal for the genus.

Dr Harborne's investigations show that the glycoside found in the flower stems does not occur in the petals or lines of the blue, purple and pink flowers tested, i.e. in flowers pigmented by malvidin or pelargonidin. Moreover, the main glycoside components are $3: 5^{-}$ dimonosides.

If it turns out that the stem glycosides never occur in the flowers, and these contain $3: 5$-dimonoside, 3-pentoseglycoside and 3-monoside as the main glycosides, then, except for the cyanidin which occurs as a minor, and significant, component of the floral pigments, pigment differentiation between floral and vegetative organs will be complete. In essence this scheme refers to a macro-pattern of cyanic pigmentation, in which floral pigmentation, like floral morphology and physiology, is seen to be a highly selected and adapted function of reproduction.

\section{(iii) Gene interaction}

A major finding of our investigation on Streptocarpus is the interaction of nearly all, perhaps all, of the major genes concerned in the production of flower pigment. The phenotypic effects embrace pigment concentration, and hydroxylation, methylation and glycosidation of the pigment molecule. Together these phenomena constitute a pigment syndrome.

When two anthocyanins occur together in the same flower, a general characteristic of the syndrome is that that pigment which has the greater number of hydroxyls in the side ring, tends to be methylated and to have the greater number of sugars. In chemical terms, the genes controlling methylation and glycosidation are more active, or efficient, in synthesis in the $O$ "background" than in the $R$, and in the $o R$ background than the or. In genetical terms, interaction tends to produce the phenotype associated with epistasy and 
dominance of the pigment genes, i.e. the wild phenotype, malvidin $3: 5$-dimonoside. Since the anthocyanidins with the greatest number of methoxyls in the side ring and the greatest number of sugars are the most stable chemically, gene interaction within the syndrome promotes phenotypic stability or homeostasis.

Had we been able to identify fully the $P$ and $M$ factors, then the syndrome might well be shown to comprise eleven independently inherited major genes, each of which could be described as a modifier (genetical) affecting anthocyanidin amount and/or kind.

The possibility of such a situation in flower-pigment production was first revealed by studies on Dahlia (Lawrence and Scott-Moncrieff, I935), where four independently inherited genes controlling the production of anthocyanidin in limited amount $(A)$, of anthocyanidin in quantity $(B)$, of butein $(Y)$ and of apigenin $(I)$ were shown each to take part in the production of a common precursor for which they also competed, production and competition being predictable on a semi-quantitative basis according to the coefficients assigned to the genes. More recently Jorgensen and Geissman ( 1955) have described the results of a critical investigation of the interaction of three single genes governing the concentration, measured spectrophotometrically, of anthocyanidin and aurone in Antirrhinum majus. Three of Geissman's findings are particularly relevant to our work with Streptocarpus, viz. (I) increased numbers of recessive factors resulted in decreased anthocyanidin production, (2) high anthocyanidin concentration is related to low aurone concentration, and vice versa, and (3) the chemical consequence of heterozygosity is an alteration in the magnitude of the effect produced by the dominant alleles.

Our results with cyanidin are of special interest. It often occurs as a minor component in the company of all three types of anthocyanidin and with all three types of glycosides. Penetrance is complete in the $o R$ class, but not in $O R$ and or classes; and approximately twice the amount of cyanidin is found in $o R$ plants as in the others.

A survey of some hundreds of species (Lawrence et al., 1939) showed that cyanidin is by far the commonest anthocyanidin in the foliage of flowering plants and it predominates in the flowers. On this evidence, and from supporting data, it was argued that whatever may be the starting point and intermediary reactions in the biosynthesis of anthocyanidins, cyanidin is the aglycone most readily produced by the plant and by the smallest number of stages. In other words, cyanidin as a final metabolic product is primitive, though not necessarily of a primitive nature (Haldane, I94I). Delphinidin and pelargonidin occur most widely in the most highly evolved plants and especially in garden plants, i.e. highly selected forms, and may therefore be described as the more highly evolved anthocyanidins. For the same reason, methylated anthocyanidins may be said to be more highly evolved than unmethylated.

The survey revealed that in a number of genera and species 
cyanidin, in small amount, accompanies delphinidin and pelargonidin as a second pigment as if it were a biosynthetic residue or by-product. This can be seen, for example, in rexii and meyeri, but it is in the garden forms of Streptocarpus that it is so prominent a feature. The fact that cyanidin occurs in equal amount in $O R$ and or classes, $O R$ comprising methylated forms and or unmethylated (because pelargonidin is never methylated) suggests that these two classes have the same constitution with respect to $M$, hence with the $O R$ class also. This view is, of course, necessitated on other grounds, i.e. nearly all garden forms are homozygous dominants for $M$. Linkage between $m$ and $R$ is thus ruled out and the preponderance of cyanidin in the $O R$ class must, on the simplest view, be attributed to interaction involving $M$ and $R$.

The corollary to the view that delphinidin and pelargonidin are more highly evolved pigments than cyanidin is that their synthesis involves additional processes or routes. Our data are of too general

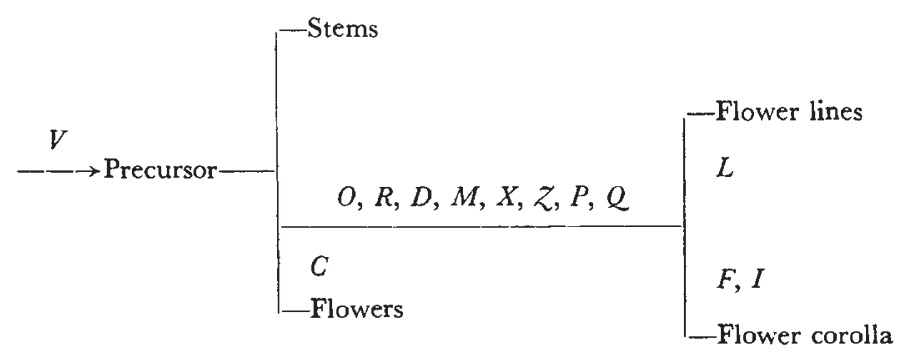

Fic. 4.-Tentative scheme for the synthesis of flower pigments in Streptocarpus.

a nature to warrant speculation on the various possibilities of cyanidin synthesis but' they do emphasise the key position of cyanidin in the synthesis, and evolution, of the anthocyanidins.

\section{(iv) Pigment synthesis}

A tentative scheme for the synthesis of anthocyanins and anthoxanthins in Streptocarpus is given in fig. 4 based on the following considerations :-

(I) $V$ controls production of a basic pigment precursor.

(2) Competition occurs in the production of chlorogenic acid and the precursor but, unlike the case with co-pigment, competition is not found between chlorogenic acid and the products of $O, R, D, M$, etc.

(3) $O, R, D$ and $M$ modify anthocyanidin in the flowers but not in the flower stems.

(4) $F$ and $I$ control general anthocyanidin production in the corolla but not in the throat lines.

\section{(v) Species}

The flowers of the great majority of Streptocarpus species examined arc pigmented by malvidin $3: 5$-dimonoside $(O D M)$ plus, in some 
cases, small amounts of unmethylated pigment. Therefore there has been strong natural selection in favour of malvidin $3: 5$-dimonoside which must have a high adaptive value.

Examination of thirty-three species hybrids has revealed a strong tendency to complete dominance of $O, D$ and $M$, i.e. of those genes with the highest frequency in the wild. Another aspect of this phenomenon concerns the dominance of $O$. This gene is a hypermorph and, further, in its presence such genes as $D, X, Z, M$ and $P$ exert their greatest effect (it is not known whether this interaction is in any sense reciprocal). $R$, another hypermorph, is hypostatic to $O$, but as it occurs in the majority of species presumably it too may have a positive adaptive value, e.g. it could augment the effect of $O$ to give this gene a still higher "safety factor". $R$, like $O$, has the power to increase the effect of $D, X, Z$ and $P$, less than does $O$, but more than does or.

The interaction effects found in the pigment syndrome were all observed in garden forms of Streptocarpus. These were derived originally from artificial crosses between rexii, parviflorus and dunnï:

$$
\begin{array}{ll}
\text { rexii } & V, F, i, O, r, D, X x Z-,-, M, C \\
\text { parviflorus } & V, f, i, O, R, D,----,-, M,- \\
\text { dunnii } & v ?, F, I, O, R, d, x \times Z Z, P, m, c
\end{array}
$$

The flower colour of dunnii is, so far, unique in Streptocarpus ; indecd this species exhibits a number of unusual, if not unique, characters and has a restricted habitat. From evolutionary, morphological and synthetic points of view, the flower pigment (cyanidin 3-pentoseglycoside) could be described as primitive and the adaptive value of $R$ as only moderate. But $R$, in the absence of $O$ in dunnii, has been fully exposed to the pressure of natural selection, hence it is of interest that dunnii, unlike rexii, also carries a gene $I$ that increases anthocyanidin production in a marked degree. $I$, in fact, could be regarded as a modifier favouring dominance of $R$ (Fisher, 1932).

These observations are based on the behaviour of $O, R$ and $I$ in the garden forms. I could only have been contributed by dunnii, but $R$ might have been derived from either parviflorus or dunnii. We have seen (tables 3,4 ) that $I$ increases the amount of pigment in all three anthocyanidin types, even though its function in dunnii appears to concern cyanidin only. Therefore $I$ must influence the synthesis of anthocyanidin at a point prior to that at which the specific nature of the anthocyanidins is determined. And $I$ is an example of how a mutation that has arisen in one specific genetic environment may have potentialities for another, should hybridisation encourage gene migration. Speculation along similar lines can be made with reference to the evolution and action of $R$, which is associated with $d$ in dunnii, and $D$ in parviflorus, but interacts with both $d$ and $D$ in the garden forms. 


\section{(vi) Evolution of flower colour}

Two major mechanisms concerned with floral pigmentation can be seen at work in the genus. The first maintains a very high percentage of cyanic forms in the wild population by adjustment of their nuclear and cytoplasmic balance. The second maintains a high percentage of blue-flowered species (malvidin $3: 5$-dimonoside), in which the pigment syndrome ensures a high level of pigment production and phenotypic and chemical stability.

A possible sequence of events in the course of evolution of the genes taking part in the synthesis of flower pigments in Streptocarpus, and other genera, can now be envisaged. The basis for a general hypothesis is as follows :

(i) Cyanidin monoside is the commonest pigment associated with the vegetative organs of flowering plants, the more complex anthocyanins being associated with the more highly evolved floral organs.

(ii) In the absence of the relevant epistatic or dominant gene, the pigment produced is less complex in structure (fewer hydroxyls, sugars), e.g. $O R$ malvidin, $o R$ peonidin ; $D$ (or $X Z)$ 3:5-dimonoside, $d x Z$ pentoseglycoside. Thus, decreased complexity is correlated with decrease in the number of dominant and epistatic genes.

(iii) Each pigment gene that has become established in the evolutionary sequence is assumed to have a higher survival value than its predecessor and to be epistatic to it, for example : $Q$ (3-monoside $) \rightarrow P$ (3-pentoseglycoside) $\rightarrow X, Z$ $(3: 5$-dimonoside in limited amount $) \rightarrow D(3: 5$-dimonoside in large amount). Further chemico-genetical analysis might reveal that other combinations of sugar type and position exist in Streptocarpus, nevertheless the same evolutionary principle could still apply.

(iv) The synthesis of a new and more complex pigment in evolution requires a new and additional process. The corollary to this requirement is that the synthesis of the new pigment does not depend sequentially on the synthesis of the old one.

(v) Increase in the total number of pigment genes demands, at least to some extent, an increase in the total amount of precursor and pigment (cf. Dahlia) hence, a higher threshold or safety factor also.

If in general such a scheme is correct then the hypostatic genes are also relic genes ; they are milestones marking the road of evolution. That they still survive could be due to their still having a function in pigment production e.g. (cf. $R$, p. $32 \mathrm{I}$ ) as accessories. 


\section{CONCLUSION}

Malvidin 3:5-dimonoside predominates as the main anthocyanin in the flowers of Streptocarpus species. It is therefore the best adapted anthocyanin. The genes mainly responsible for the deternination of anthocyanidin type $(O, R)$ are hypermorphs.

The activity of other genes taking part in anthocyanin production and modification is at a higher level in the presence of $O$, and $R$ than in their absence. The genes show independent inheritance. All together, they comprise a syndrome of interacting units which promote chemical and phenotypic stability, i.e. homeostasis. Evolution of flower colour appears to have been by successive genes mutating, becoming dominant and finally epistatic to their predecessors.

\section{SUMMARY}

I. A survey is made of flower colour in the genus Streptocarpus, in the garden forms and in species and hybrids. Anthocyanins and anthoxanthins are identified, their inheritance demonstrated and gene action discussed.

2. The anthocyanins are derivatives of delphinidin, cyanidin and pelargonidin. The glycosides are 3:5-dimonoside, 3-pentoseglycoside and 3-monoside. The anthoxanthins are a co-pigment, probably apigenin, and chlorogenic acid. The phenotypic effect of the genes concerned in floral pigmentation is deduced as follows.

\section{Gene action}

3. $V$ produces cyanidin glycosides in flower stems and leaves. When $F$ is present also, anthocyanin is produced in the flowers, its nature depending on the presence or absence of other dominant genes.

4. In $O(R), o R$ and or flowers the anthocyanidin types are delphinidin, cyanidin and pelargonidin respectively. $O$ is epistatic to $R$. In the presence of $M$, the anthocyanins are malvidin, peonidin and pelargonidin.

5. In the presence of $D, 3: 5$-dimonoside is produced in quantity. In $d$ flowers, $3: 5$-dimonoside is produced in limited amount in the presence of the complementary genes $X$ and $Z$, the accompanying pigment being 3-pentoseglycoside or 3 -monoside.

6 . The production of 3 -pentoseglycoside and 3 -monoside is postulated to be governed by other independent genes, $P$ and $Q$.

7. Cyanidin is frequently a minor component in peonidin types but much less frequently and in much smaller amount in malvidin and pelargonidin types.

8. $C$ controls the production of a co-pigment, probably apigenin. Chlorogenic acid occurs as a non-co-pigment in all flowers tested.

9. The inheritance of $V, O, R, D$ and $C$ is Mendelian and independent. 


\section{Varieties and species}

IO. In a relatively unbiased population of 133 garden forms of Streptocarpus, interaction was found to occur between all the pigment genes, which together constitute a syndrome promoting chemical and phenotypic stability, i.e. homeostasis.

I I. Eighteen species tested were pigmented wholly or mainly by malvidin $3: 5$-dimonoside $(O M D)$ and this anthocyanin was found to predominate in 33 crosses between species. In the wild, therefore, malvidin $3: 5$-dimonoside has a high adaptive value.

12. A high percentage of cyanic phenotypes is maintained in the wild population by adjustment of the nuclear and cytoplasmic balance of the species.

13. The hypothesis is advanced that the evolution of flower colour in Streptocarpus has been by successive genes mutating, becoming dominant and, finally, epistatic to their predecessors.

Acknowledgment.-We wish to express our indebtedness to Dr J. R. Price, onetime Head of the Chemistry Section at the John Innes Institution, for valuable help and advice, and identification of some of the flower pigments in Streptocarpus.

\section{REFERENCES}

BE:LLE, G. H., ROBINSON, G. M., ROBINSON, ROBERT, AND SCOTT-MONCRIEFF, R. I939. Genetics and Cihemistry of flower colour variation in Lathyrus odoratus. $\mathcal{J}$. Genet., 37, 375-388.

BEAle, G. H. I94I. Gene relations and synthetic processes. J. Genet., 42, i97-2 I4. CROWE, L. K. I95j. The evolution of incompatibility in species of Enothera. Heredity, 9, 293-322.

FISHER, R. A. I932. The evolution of dominance. Biol. Rev., 6, 345-368.

haldane, J. B. S. 1939. The theory of the evolution of dominance. $\mathcal{J}$. Genet.; $37,365-374$.

hialdane, J. B. S. I941. New Paths in Genetics. London.

JORGENSEN, E. C., AND GEISSMAN, T. A. I 955. The chemistry of flower pigmentation in Antirrhinum majus colour genotypes. III. Relative anthocyanin and aurone concentrations. Arch. Biochem. and Biophys., 55, 389-402.

i.AWRENCE, W. J. C., PRICE, J. R., ROBINSON, G. M., AND ROBINSON, R. i939. The distribution of anthocyanins in flowers, fruits and leaves. Phil. Trans. Roy. Soc. B., 230, I 49-1 78.

LAWRENCE, W. J. C., SCOTT-MONCRIEFF, R., AND STURGESS, V. C. I939. Studies on Streptocarpus. I. Genetics and chemistry of flower colour in the garden strains. J. Gen., 38, 299-306.

MCLLER, H. J. I932. Further studies on the cause of gene mutations. Proc. 6th Int. Cong. Gen., I, $213-255$.

robinson, G. M., AND Robinson, R. ig3i. A survey of anthocyanins, i. Biochem. 7 ., 25, I $687-1705$.

ROBINSON, G. M., AND ROBINSON, R. 1932. A survey of anthocyanins, 2. Biochem. 7 ., $26,1647-1664$.

SCOTT-MONCRIEFF, R. I939. The genetics and biochemistry of flower colour variation. Ergeb. Enzymforschung, 8, 277-306

STOREy, R. I953. Botanical Survey Officer, Union of South Africa. Private communication. 


\section{APPENDIX \\ Identification of pigments}

Anthocyanins were fully identified by means of the qualitative tests devised by Robinson and Robinson, 1931, 1932.

The-glycoside types were distinguished by their distribution to iso-amyl alcohol. At low concentrations monosides are extracted by the organic layer up to 30 to 40 per cent. (according to the degree of oxidation of the anthocyanidin, pelargonidin derivatives having the highest distribution) pentoseglycosides are extracted scarcely at all and dimonosides not at all. If the solutions are then saturated with salt the monosides and pentoseglycosides are both completely extracted but the distribution of the dimonosides is unchanged.

For complete identification of the anthocyanin pigments, flowers, after removal of corolla tubes, were stored in bottles in I per cent. aqueous $\mathrm{HCl}$. The crude extract was filtered and tested for co-pigment and other anthoxanthins. If present, these were removed by repeated extraction with ethyl acetate. The solution was finally washed with benzene and filtered.

A portion of the purified extract was saturated with salt and shaken with an equal volume of amyl alcohol. If no pigment was extracted by the acohol the anthocyanin was diglycosidic and was then hydrolysed straight away. If, however, some or all of the pigment passed into the alcohol layer it was necessary to separate the glycosidal types by saturating the whole of the solution with salt and extracting exhaustively with amyl alcohol. The combined amyl alcohol extracts were filtered and the pigment returned to $\mathrm{x}$ per cent. aqueous $\mathrm{HCl}$ by the addition of much light petroleum. By this means, the pigments with high distribution were separated from the dimonosides. Each fraction was examined separately, the glycosidal types identified and the approximate percentage of the whole which each fraction represented estimated by colorimetric comparison of the I per cent. aqueous $\mathrm{HCI}$ solutions.

The presence of 3-monosides in Streptocarpus was demonstrated by comparing colorimetrically the distribution to iso-amyl alcohol of the purified high distribution fraction from a rose-coloured flower in a per cent. aqueous $\mathrm{HCl}$, with the distributions given by comparable solutions of pure crystalline 3 -monosides of cyanidin and malvidin. (Results : cyanidin 3-monoside 29.8 per cent., malvidin 3-monoside 22.9 per cent, and high distribution fraction from rose-coloured flower 25.7 per cent.).

The anthocyanidins obtained following the hydrolysis of the glycosides were identified by Robinson and Robinson's aglycones qualitative tests. In many Streptocarpus garden forms there is a mixture of anthocyanidins as well as sugar types. These were separated by making use of the different distributions displayed by the anthocyanidins to the "cyanidin reagent" and "delphinidin reagent" of Robinson and Robinson. A complete separation cannot always be achieved but cyanidin, which is the unmethylated type most frequently found in the garden forms, can always be identified as it is the only pigment extracted by "cyanidin reagent" that gives a positive ferric reaction. 